\title{
Intellectual Property Protection and the Industrial Composition of Multinational Activity
}

\author{
Olena Ivus, Walter Park, and Kamal Saggi*
}

\begin{abstract}
In a North-South model with endogenous FDI, we examine the impact of Southern IPR protection on the mode and industrial composition of international technology transfer. A novel feature of the model is that, due to technological reasons, industries differ with respect to their susceptibility to imitation. In equilibrium, licensing occurs in industries where the risk of imitation is low and FDI where it is of intermediate magnitude. Stronger IPRs in the South (i) alter the industrial composition of multinational activity towards licensing at the expense of FDI; (ii) reduce local imitation; and (iii) increase licensing and, to a lesser extent, FDI.
\end{abstract}

Keywords: Intellectual property rights; Trade; FDI; Licensing; Technology transfer

JEL classification: F10; O34

* Olena Ivus: Smith School of Business, Queen's University, Goodes Hall, 143 Union Street, Kingston, ON K7L 3N6, Canada. E-mail: oivus@business.queensu.ca. Walter Park: Department of Economics, The American University, Washington, D.C. 20016, USA. E-mail: wgp@american.edu. and Kamal Saggi: Department of Economics, Vanderbilt University, PMB 351828, 2301 Vanderbilt Place, Nashville, TN 37235, USA. E-mail: k.saggi@vanderbilt.edu. The authors would like to thank Nancy Gallini, Jordi Mondria, and participants of the Canadian Economics Association conference (2013) for their helpful comments. The paper includes some calculations based on firm level data on U.S. multinational companies and their foreign affiliates. This analysis was conducted at the Bureau of Economic Analysis, United States (U.S.) Department of Commerce under arrangements that maintain legal confidentiality requirements. Views expressed in this paper are those of the authors and do not necessarily reflect official positions of the U.S. Department of Commerce. 


\section{Introduction}

The conclusion of the last successful round of multilateral trade negotiations in 1995, i.e. the Uruguay Round, formally marked the emergence of the World Trade Organization (WTO). Another notable achievement of the Uruguay Round was the ratification of the Agreement on TradeRelated Aspects of Intellectual Property Rights (TRIPS). As is well known, major developing countries resisted this multilateral agreement almost as fiercely as it was promoted by the United States and the European Union. An important source of the conflict had to do with how the two sides viewed, and to some extent continue to view, the likely impact of strengthening intellectual property rights (IPRs) protection in developing countries on international technology transfer to their markets. Indeed, as per Article 7 of TRIPS an important objective of the agreement is that: "the protection and enforcement of intellectual property rights should contribute...to the transfer and dissemination of technology to the mutual advantage of producers and users of technological knowledge." If achieved, increased technology transfer would be viewed as just compensation by developing countries in return for making their intellectual property regimes TRIPS compliant. However, this outcome is hardly guaranteed; the actual impact of TRIPS on the transfer of technology is likely to depend on a complex set of interactions in the global economy. For example, while stronger IPRs may encourage technology transfer through market-based channels such as foreign direct investment (FDI) and licensing, they simultaneously restrict the transfer of technology through non-market channels such as imitation and reverse-engineering. 1 The net effect of these opposing tendencies on aggregate technology transfer is far from obvious.2

One factor likely to be important in determining the overall effect of TRIPS on multinational activity and technology transfer is the variation in imitation risk across industries. For example, it is often argued that patent protection is crucial for incentivizing innovation in the pharmaceutical industry because the cost of imitating a typical medicinal drug is minuscule relative to the cost of inventing one. Indeed, the relative ease of imitation and the non-enforcement of foreign patents allowed a developing country such as India to successfully establish a local pharmaceutical industry prior to the ratification of the TRIPS agreement. On the other hand, firms in most developing countries have found it extremely difficult, and usually outright impossible, to imitate complex manufactured goods such as automobiles and airplanes even though local IPR policy (prior to

\footnotetext{
${ }^{1}$ Of course, imitation and reverse-engineering are non-market based only in the sense that innovators do not directly participate in and benefit from these activities. In every other sense these activities are market based since, like innovators, imitators respond to the profit incentive provided by the market place - see Grossman and Helpman (1991).

${ }^{2}$ Empirical evidence is generally favorable to the idea that stronger IPR protection in the South generates more technology transfer via licensing and FDI - see the specific evidence in Lee and Mansfield (1996), Branstetter, Fisman, and Foley (2006), Branstetter et al. (2011), Javorcik (2004), and the overview discussion in Maskus (2000) and Park (2008). However, imitation is difficult to measure with any real precision because it is not market mediated like licensing and FDI.
} 
TRIPS) hardly prevented them from doing so.

Data exist that strongly support these premises ${ }^{3}$ For example, in the case of technology transfers of U.S. multinational firms in developing countries in the manufacturing industry, the average firm's arms-length licensing is less than $30 \%$ of its total licensing. This smaller share of unaffiliated licensing in total licensing reflects the greater 'imitation risk' associated with conveying technological information to external parties compared to keeping information internal within the subsidiary. Furthermore, the average firm's share of unaffiliated licensing in total licensing varies across different manufacturing industries and corresponds with the variation in imitation risk across sectors. For example, in the pharmaceutical industry, per firm, unaffiliated licensing is about $10 \%$ of total licensing. In the non-pharmaceutical chemical industry, this share is approximately $15 \%$. In contrast, per firm, nearly half of all licensing in the equipment industry and about $45 \%$ in the transportation industry (i.e., motor vehicles and aerospace) is to unaffiliated parties. The overall volume of licensing, across firms, in the transportation and equipment industries is also much greater than in the chemicals industry; for example, the chemical industry as a whole (including pharmaceuticals) accounts for one-fifth of total arms-length licensing in the manufacturing industry, while equipment and transportation account for two-thirds. Thus, a greater level and share of unaffiliated licensing occurs in industries that produce technologically sophisticated products, the underlying technologies of which are complex in that they "cannot be understood in detail by an individual expert and communicated precisely among experts" (Rycroft and Kash, 1999). The sophistication of these products is an inherent barrier to technological leakage, thereby limiting imitation. In contrast, pharmaceutical and other chemical products are characterized by technologies that are simple and easy to detail, making their imitation relatively easier.

These observations suggest that to obtain a more nuanced understanding of the consequences of changes in IPR protection in developing countries necessitated by TRIPS, it is important to account for the fact that imitation risk, and indeed the value of patent protection, varies across industries. Yet, existing analyses of IPR protection in an international setting have generally tended to ignore the variation in imitation risk across industries - see, for example, the classic works of Grossman and Helpman (1991) and Helpman (1993) and the more recent contribution of Branstetter and Saggi (2011).

In this paper, we develop a simple general equilibrium model of an innovative North and an

\footnotetext{
${ }^{3}$ These data are based on surveys of multinational firms and trade in services conducted by the U.S. Bureau of Economic Analysis (BEA) - namely, the BE-11, BE-093, and BE-125 surveys - and our own calculations. The measure of licensing referred to in this section is licensing fees and royalty receipts earned by parent firms from affiliates and unaffiliated parties in 89 developing countries over the 1992-2009 period.

${ }^{4}$ For example, the complexity of industrial machinery products makes imitation costly, whether or not the products are patented (Levin et al., 1987).
} 
imitative South in which there exists a continuum of industries that differ with respect to their technological complexity and therefore in the risk of imitation faced by them. Each industry is populated by firms that produce differentiated products. Imitation begins with technology leakage to the South. Once Southern firms imitate a novel Northern technology, they begin local production of the imitated product in the South. The risk of Southern imitation is high when the technology is easy to specify and communicate. A Northern firm seeking access to the Southern market is faced with the choices of: (i) producing in the North; (ii) establishing a fully owned subsidiary in the South (i.e., undertaking FDI); or (iii) licensing its proprietary technology to an arm's length Southern firm. Each of these choices entails its own costs and risks. Confining production to the North eliminates technology leakage to Southern firms and so entails no imitation risk, but precludes the cost savings arising from lower wages in the South. Undertaking FDI takes advantage of lower Southern wages, but also carries the cost of establishing a subsidiary as well as the risk of imitation $5^{5}$ Finally, arm's length licensing avoids both the costs of establishing a subsidiary and the higher wages in the North, but requires some form of profit sharing and also carries the highest risk of imitation.

Since industries can be ranked in our model according to their level of technological sophistication (which in turn determines the risk of imitation faced by them), two threshold levels of technological sophistication determine equilibrium mode choices. To the left of the first threshold are complex product industries, where the risk of imitation is quite low. In these industries, Northern firms transfer their proprietary technology to the South via arms length licensing contracts. To the right of the second threshold are discrete product industries, where the risk of imitation is so high that Northern firms choose to retain production in their home market. Industries that lie in the middle-ground between the two thresholds are the ones that end up establishing production in the South via FDI. Consequently, the range of industries in which technology is transferred through imitation, licensing, and FDI is endogenously determined in our model.

This configuration of industries, as described, is consistent with the empirical analysis of Ivus et al. (2015), who analyze a large data-set of the FDI undertaken by U.S. multinational firms. Ivus et al. (2015) report that the volume of arm's length licensing is greater among firms in complex product industries than among those operating in discrete product industries. The present paper provides a theoretical framework for explaining observed industry differences in the mode of international technology transfer on the basis of industry level variation in imitation risk.

\footnotetext{
${ }^{5}$ Shifting production to the South introduces a higher risk of imitation because local employees can misappropriate the firm's technology to start up imitative production - see Ethier and Markusen (1996), Markusen (2001), Glass and Saggi (2002a), and Poole (2013). Empirical evidence indicates that even in an advanced economy such as the United Kingdom, geographic proximity is an important factor determining the speed at which the productivity of lagging firms catches up to that of firms on the technology frontier - see Griffith et al. (2009).
} 
For instance, by directly lowering imitation, a strengthening of IPR protection in the South affects technology transfer in two ways. First, within each industry, multinational production (carried out via licensing or FDI) expands at the expense of imitated production. This withinindustry shift is strongest in industries where IPRs are most effective, i.e., in industries that have the lowest level of technological complexity. Second, the total number of industries that engage in multinational activity increases as intellectual property becomes more secure in the South. This increase in the extensive margin of multinational activity is driven primarily by an increase in the number of industries engaged in licensing. In fact, the set of industries in which FDI occurs does not necessarily increase and can even shrink. This result resonates quite well with a key insight of the literature that explains the emergence of multinational firms: the incentive to internalize transactions by establishing a wholly owned subsidiary in a foreign country declines when market exchange of technology across national borders becomes more secure - see Markusen $(1995,2001)$ and Ethier and Markusen (1996).

An interesting implication of the model is that, while stronger IPR protection in the South lowers the imitation risk facing all Northern industries, a greater number of industries are willing to become potential targets of Southern imitators due to the overall expansion in multinational activity. The model also predicts that a strengthening of Southern IPR protection reduces technology transfer to the South through imitation although licensing and FDI play competing roles in this result. While Southern production derived from imitation of FDI decreases, that derived from imitation of industries with licensing increases. Since imitation in industries where licensing serves as the channel of international technology transfer is low to begin with, the reduction in imitative production within each such industry is small. At the same time, the expansion in licensing activity across industries is strong so that the scope for imitation of licensed technologies rises by creating more industries in which licensing occurs. Industries in which FDI is the preferred means of Southern production respond differently: here, the reduction in imitated production within each industry is relatively large whereas the expansion in imitated production across industries is weaker. As a result, post IPR reform, FDI becomes a less important source of imitation for the South.

The major modeling contribution of the paper is to bring together licensing, FDI, and imitation in a simple general equilibrium model wherein imitation risk varies across industries. ${ }^{6}$ Yang and Maskus (2001) provide an analysis of the effects of Southern IPR protection in a North-South product cycle model where technology transfer occurs via licensing but they do not consider FDI while Glass and Saggi (2002b) consider both licensing and FDI but ignore imitation. In our model,

\footnotetext{
${ }^{6}$ Ivus (2011) also permits imitation risk to differ across industries but does not allow Northern innovators to undertake multinational activity of any type.
} 
the choice between licensing and FDI is based on the relative risk of imitation confronting the two arrangements, the rent sharing involved under licensing, and the costs of undertaking FDI. Since our interest is in the implications of internalization, we take these features of licensing and FDI to be given. An alternative approach would be to motivate internalization from the ground up by explicitly modeling the incompleteness of the licensing contract relative to FDI.7. For example, Antràs (2005) has developed a North-South product cycle model with ongoing standardization where the incompleteness of international contracts determines the choice between arms length technology transfer and FDI.

More recently, in an insightful contribution Bilir (2014) develops and empirically tests a model in which the FDI decisions of firms depend upon the respective life cycles of the products sold by them. She argues that firms selling products with shorter life cycles are less sensitive to imitation risk because imitation is less likely to occur before obsolescence. Like us, her model captures the idea that the risk of imitation faced by firms from developed countries varies across industries and that such variation should affect the composition and extent of multinational activity. However, unlike Bilir (2014), the model we develop is general equilibrium in nature and the endogeneity of wages plays an important role in our analysis. Second, we consider how IPR protection affects the choice between licensing and FDI, an important question that is not addressed by Bilir's analysis.

The rest of the paper proceeds as follows. Section 2 develops the model while section 3 describes its equilibrium. In section 4 we analyze the impact of a strengthening of Southern IPR protection on the magnitude and composition of multinational activity. Section 5 discusses the empirical implications and section 6 provides a brief conclusion. All necessary derivations and proofs are contained in the Appendix.

\section{$2 \quad$ Model}

Assume the world consists of two regions: an innovative North and an imitative South. A continuum of industries indexed by $z \in[0,1]$ exists, with each industry being composed of $n(z)$ innovated products and $n^{*}(z)$ imitated products. Innovation is proportional to the total number of products $N(z)$ already in existence in industry $z$, where $N(z)=n(z)+n^{*}(z)$. As such, the total number of products within each industry evolves according to $\dot{N}(z)=g N(z)$, where $g$ is the constant (and exogenous) innovation rate. Imitation is proportional to the number of innovated products in industry $z$. The number of imitated products evolves according to $\dot{n}^{*}(z)=m(z) n(z)$, where

\footnotetext{
${ }^{7}$ Ethier (1986) provides an early general equilibrium model of internalization based on such an approach.
} 
$m(z)$ is the industry-specific imitation rate. In the steady state, the relative number of imitated products is $\eta(z) \equiv n^{*}(z) / n(z)=m(z) / g \square^{8}$

To model cross-industry variation in imitation, we let imitation rate depend on the industry index $z$ as follows: $m(z) \equiv \mu z$. As is clear, the rate of imitation rises with $z$. Imitation is low in low $z$ industries composed of complex products, and high in high $z$ industries composed of discrete products. The imitation rate also depends upon the strength of Southern IPR protection, captured by the parameter $\mu$. By assumption, IPRs are perfectly enforced in the North so that $\mu=0$ in a Northern industry $z$. In the South, the enforcement of IPR protection is weak and $\mu>0$.

Depending on the imitation rate $m(z)$, Northern firms in each industry decide whether to: (i) produce in the North; or (ii) establish a fully owned subsidiary in the South (i.e. FDI); or else, (iii) directly license their proprietary technology to arm's length Southern firms. Confining production within the North avoids imitation. FDI is relatively more risky, since it requires firms to transfer proprietary technical information to their subsidiaries in the South, which in turn may be misappropriated by the subsidiary's employees and used to start up imitative production (Ethier and Markusen, 1996; Markusen, 2001; Glass and Saggi, 2002a; and Poole, 2013). Greater still is the imitation risk when technology is transferred through licensing. While FDI involves technology transfer to a wholly owned subsidiary (i.e. a controlled non-arm's length entity), licensing involves sharing technology with arm's length Southern firms which are generally independent of control. As is known from the work of Horstmann and Markusen (1987), the inability of the firm to control the actions of a licensee creates an incentive to internalize transactions through FDI. Following this discussion, we specify the imitation rate as follows:

$$
m(z) \equiv \begin{cases}0 & \text { if industry } z \text { produces in the North } \\ \mu z & \text { if it undertakes FDI } \\ \iota \mu z & \text { if it licenses its technology }\end{cases}
$$

so that $\iota>1$ measures the licensing risk premium 9

Consistent with the existing literature, we model a strengthening of Southern IPR protection as a reduction in the risk of imitation across all industries as captured by the parameter $\mu$. While stronger IPR protection in the South lowers the imitation risk in all industries, the impact is strongest in high $z$ discrete product industries. Products in these industries depend on the

\footnotetext{
${ }^{8}$ The relative number of imitated products within each industry changes over time according to $\dot{\eta}(z)=m(z)-$ $g \eta^{2}(z)-[g-m(z)] \eta(z)$. Setting $\dot{\eta}(z)$ to zero, we find that the steady state relative number of imitated products in each industry is $\eta(z)=m(z) / g$.

${ }^{9}$ Since there is no imitation in the North, the total number of products within each Northern industry $z$ is $N(z)=n(z)$.
} 
strength of IPRs the most because their underlying technologies can be easily communicated and misappropriated. Moreover, patent protection is strong in these industries, because their underlying technologies are simple enough that they can be easily described in a patent and inventing around a discrete product patent is hard. Anand and Khanna (2000) note in this respect that a pharmaceutical patent is hard to invent around "since a slight change in the underlying gene sequence of a protein can result in very different functions." By contrast, IPR protection is relatively ineffective in low $z$ complex product industries, because it is difficult to clearly describe the knowhow embodied in the underlying technologies in a patent and so prevent patent infringement. Our assumption about the cross-industry difference in the impact of IPR protection is well supported by empirical evidence. For example, Mansfield et al. (1981) and Levin et al. (1987) found that patents raise imitation costs by 30-40 percentage points in drugs and 15-7 points in electronics.

\section{$2.1 \quad$ Tastes}

The two regions have identical tastes. The instantaneous utility function of the representative consumer is given by:

$$
U=\int_{0}^{1} b(z) \ln [c(z)] d z, \quad c(z)=\left[\sum_{i=0}^{N(z)} c_{i}^{\gamma}(z)\right]^{1 / \gamma}
$$

where $c_{i}(z)$ denotes the consumption of product $i$ in industry $z$. $\gamma=(\sigma-1) / \sigma$, with $\sigma>1$ being the constant elasticity of substitution in consumption, $b(z)$ is the budget share spent on products of industry $z$, and $\int_{0}^{1} b(z) d z=1$. We assume that the budget share is the same across all $z$ so that $b(z)=1$.

The demand for product $i$ in industry $z$ is as follows:

$$
c_{i}(z)=\frac{p_{i}^{-\sigma}(z) E}{P^{1-\sigma}(z)}
$$

where $p_{i}(z)$ is the price of product $i$ in industry $z, P(z) \equiv\left[\sum_{i=0}^{N(z)} p_{i}^{1-\sigma}(z)\right]^{1 /(1-\sigma)}$ is the overall price index for industry $z$, and $E$ is total expenditure. 


\subsection{Technologies and Endowments}

The North and the South are endowed with $L$ and $L^{*}$ units of labour respectively. One unit of labour produces one unit of output in both regions and no labour is required for innovation or imitation (since these are assumed to be exogenous).

A Northern firm charges a monopoly price as long as its product has not been imitated. Given the preferences specified in (2), the standard monopoly-pricing rule applies to innovated products. For any Northern product, the price $p$ equals a fixed mark-up above marginal costs of $w$; hence $p=w / \gamma$. For any innovated product manufactured by a Southern subsidiary or a licensee, the price $p_{M}$ equals a fixed mark-up above marginal costs of $w^{*}$; hence $p_{M}=w^{*} / \gamma$. Once an innovated product is imitated, it is in the public domain and thus, imitated products are competitively priced: $p^{*}=w^{*}$.

\subsection{Production Decisions}

Let $V^{j}(z)$ represent the expected present discounted value of the stream of profits for a Northern firm which engages in one of the three activities: Northern production $(j=N)$, FDI $(j=F)$, or licensing $(j=\Lambda)$. At every point in time, the Northern firm in each industry chooses the maximum of the three options given by $V(z) \equiv \max \left[V^{N}(z), V^{F}(z), V^{\Lambda}(z)\right]$. The expected present discounted value of the stream of profits from Northern production is $V^{N}(z)=\pi^{N}(z) / r$, where $\pi^{N}(z)$ denotes instantaneous profits earned by producing in the North and $r$ the discount rate. A Northern firm that engages in FDI or licensing faces the risk of imitation. Once imitation occurs, the Northern firm's future profits are driven to zero. Hence, the expected present discounted value of the stream of profits from these two activities are risk-adjusted: $V^{F}(z)=\pi^{F}(z) /[r+\mu z]$ and $V^{\Lambda}(z)=\pi^{\Lambda}(z) /[r+\iota \mu z] \cdot 10$

The instantaneous profits a firm earns from Northern production are given by $\pi^{N}(z)=[p-$ $w] y(z)$, where $p=w / \gamma$ and the output per product is $y(z)=p^{-\sigma}\left(E+E^{*}\right) / P^{1-\sigma}(z)$. FDI requires a firm to incur a cost of setting up and managing production in the South. We assume a proportion $(1-\tau)$ of output is used to cover these investment costs and so instantaneous profits under FDI are

\footnotetext{
${ }^{10}$ If a Northern firm decides to engage in FDI, then in a small time interval of length $d t$ it earns a stream of profits $\pi^{F}(z, t) d t$. The probability of imitation in a time interval $d t$ equals $\mu z d t$. With probability $\mu z d t$, future profits are zero. With probability $1-\mu z d t$ the Northern firm earns future profits, which are discounted at the rate of $r d t$. The expected present discounted value of the stream of profits from FDI is $V^{F}(z, t)=\pi^{F}(z, t) d t+[1-r d t][1-$ $\mu z d t] V^{F}(z, t+d t)$. Rearranging, we obtain: $\left[V^{F}(z, t+d t)-V^{F}(z, t)\right] / d t=[r+[1-r d t] \mu z] V^{F}(z, t+d t)-\pi^{F}(z, t)$. Now letting $d t$ approach zero and simplifying, we find that $\dot{V}^{F}(z, t)=[r+\mu z] V^{F}(z, t)-\pi^{F}(z, t)$. In steady state, $\dot{V}^{F}(z, t)=0$ and so, $V^{F}(z)=\pi^{F}(z) /[r+\mu z]$.
} 
given by $\pi^{F}(z)=\tau\left[p_{M}-w^{*}\right] y_{M}(z)$, where $p_{M}=w^{*} / \gamma$ and $y_{M}(z)=p_{M}^{-\sigma}\left(E+E^{*}\right) / P^{1-\sigma}(z)$. Licensing involves rent sharing with the Southern licensee.11] If $\lambda$ denotes the Northern licensor's share of profits then its instantaneous profits under a licensing agreement are $\pi^{\Lambda}(z)=\lambda\left[p_{M}-w^{*}\right] y_{M}(z)$.

Of note, we allow the licensor's rent share to depend upon the strength of IPRs and industry: $\lambda=\lambda(\mu, z)$. The licensor's rent share is expected to be positively related to the strength of Southern IPRs (i.e., negatively related to $\mu$ ). IPR protection affects the nature of the licensing contract; it reduces the costs of achieving mutually agreeable licensing contracts and strengthens the licensor's bargaining power (Yang and Maskus, 2001). Also, patents generally increase imitation costs across industries (Mansfield et al., 1981; Levin et al., 1987) and so are expected to reduce $\mu$ and increase $\lambda$. Gallini and Wright (1990) further show that in the presence of asymmetric information, a licensor will find it optimal to share rents with the licensee to deter imitation, with the degree of rent sharing declining with imitation costs. As such, the licensor's rent share is also expected to be negatively related to the industry index $z$. The risk of imitation is low in low $z$ industries and so, the share of rents earned by the licensor is expected to be higher. It proves useful to define the Northern licensor's rent share as follows:

$$
\lambda(z) \equiv \frac{\lambda_{0}}{1+\mu z}
$$

The rent share is negatively related to the imitation rate $\mu z$. It is at its maximum of $\lambda_{0}$ when IPRs are perfectly enforced in the South $(\mu=0)$. When $\mu>0$, the rent share falls from its maximum of $\lambda_{0}$ at $z=0$ to its minimum of $\lambda_{0} /(1+\mu)$ at $z=1$.

A Northern firm in industry $z$ will choose FDI over Northern production if risk-adjusted profits from FDI exceed profits from Northern production: $\pi^{F}(z) /[r+\mu z]>\pi^{N}(z) / r$. Using the solutions for $\pi^{N}(z)$ and $\pi^{F}(z)$, we find:

$$
V^{F}(z)>V^{N}(z) \quad \text { if } \quad \frac{\pi^{F}(z)}{r+\mu z}>\frac{\pi^{N}(z)}{r} \quad \text { or } \quad \tau \omega^{\sigma-1}>1+\frac{\mu z}{r},
$$

where $\omega \equiv w / w^{*}$ is the relative Northern wage. Similarly, a Northern firm in industry $z$ will choose licensing over Northern production and over FDI if profits from licensing, adjusted for high risk, are sufficiently high:

$$
V^{\Lambda}(z)>V^{N}(z) \quad \text { if } \quad \frac{\pi^{\Lambda}(z)}{r+\iota \mu z}>\frac{\pi^{N}(z)}{r} \quad \text { or } \quad \lambda(z) \omega^{\sigma-1}>1+\frac{\iota \mu z}{r} .
$$

\footnotetext{
${ }^{11}$ It is generally acknowledged that the market for technology licensing is imperfect (e.g., due to limited information and uncertainty in the outcomes of licensing transactions) and that these imperfections limit the licensor's ability to extract rents from the licensee. See the classic paper by Caves et al. (1983) and the ample literature inspired by it.
} 


$$
V^{\Lambda}(z)>V^{F}(z) \quad \text { if } \quad \frac{\pi^{\Lambda}(z)}{r+\iota \mu z}>\frac{\pi^{F}(z)}{r+\mu z} \quad \text { or } \quad \frac{\lambda(z)}{\tau}>\frac{r+\iota \mu z}{r+\mu z}
$$

Rewriting (5)-(7) as equalities and using (4), we find three equalized profits schedules:

$$
\begin{gathered}
F\left(\bar{z}_{F}, \omega\right) \equiv \tau \omega^{\sigma-1}-1-\frac{\mu \bar{z}_{F}}{r}=0 ; \\
\Lambda\left(\bar{z}_{\Lambda}, \omega\right) \equiv\left(\frac{\lambda_{0}}{1+\mu \bar{z}_{\Lambda}}\right) \omega^{\sigma-1}-1-\frac{\iota \mu \bar{z}_{\Lambda}}{r}=0 ; \\
Z(\bar{z}) \equiv \frac{1}{\tau}\left(\frac{\lambda_{0}}{1+\mu \bar{z}}\right)-\frac{r+\iota \mu \bar{z}}{r+\mu \bar{z}}=0 .
\end{gathered}
$$

The schedule $F\left(\bar{z}_{F}, \omega\right)$ associates with each value of the relative Northern wage $\omega$ a cut-off industry $\bar{z}_{F}$ such that the expected present value of the stream of profits a Northern firm receives from FDI is equal to the expected present value of the stream of profits from Northern production. Similarly, the schedule $\Lambda\left(\bar{z}_{\Lambda}, \omega\right)$ associates with each value of $\omega$ a cut-off industry $\bar{z}_{\Lambda}$ such that the expected present value of licensing is equal to that of Northern production. Both schedules are positively sloped because a higher relative wage in the North implies a greater cost advantage arises from producing in the South. Both licensing and FDI are thus more profitable than Northern production, and Northern firms in new industries decide to face the risk of imitation associated with producing in the South. 12

The schedule $Z(\bar{z})$ defines a cut-off industry $\bar{z}$ in which firms are indifferent between licensing and FDI. A Northern firm's choice between licensing and FDI is independent of the relative Northern wage $\omega$, and depends on parameters $\lambda_{0}, \tau, r, \iota$, and $\mu$. We assume that these parameters satisfy the following inequality:

$$
\tau\left[\frac{(1+\mu)(r+\iota \mu)}{r+\mu}\right]>\lambda_{0}>\tau,
$$

so that relative to FDI, licensing is more profitable in the industry with no imitation risk (i.e., for $z=0$ ) but less profitable in the industry with highest risk (i.e., at $z=1$ ). It follows from (7) that when $z=0$, licensing is preferred over FDI if the proportion of profits a Northern firm retains from licensing exceeds the proportion it retains from FDI: $\lambda_{0}>\tau$. When $z=1$, FDI is preferred over licensing if the licensing risk-premium $\iota$ is such that the risk-adjusted profits the Northern firm retains from FDI exceeds the share of risk-adjusted profits it obtains from licensing: $\tau /[r+\mu]>\lambda_{0} /[(1+\mu)(r+\iota \mu)]$.

\footnotetext{
${ }^{12}$ The rate at which $\bar{z}_{\Lambda}$ and $\bar{z}_{F}$ rise as $\omega$ goes up depends on the elasticity of substitution, $\sigma$. If $\sigma<2$, the profitability of FDI and licensing relative to Northern production rises slowly and so $\bar{z}_{\Lambda}$ and $\bar{z}_{F}$ rise slowly as $\omega$ goes up. In other words, Northern and Southern labour are poor substitutes and so, a larger adjustment in $\omega$ is
} 


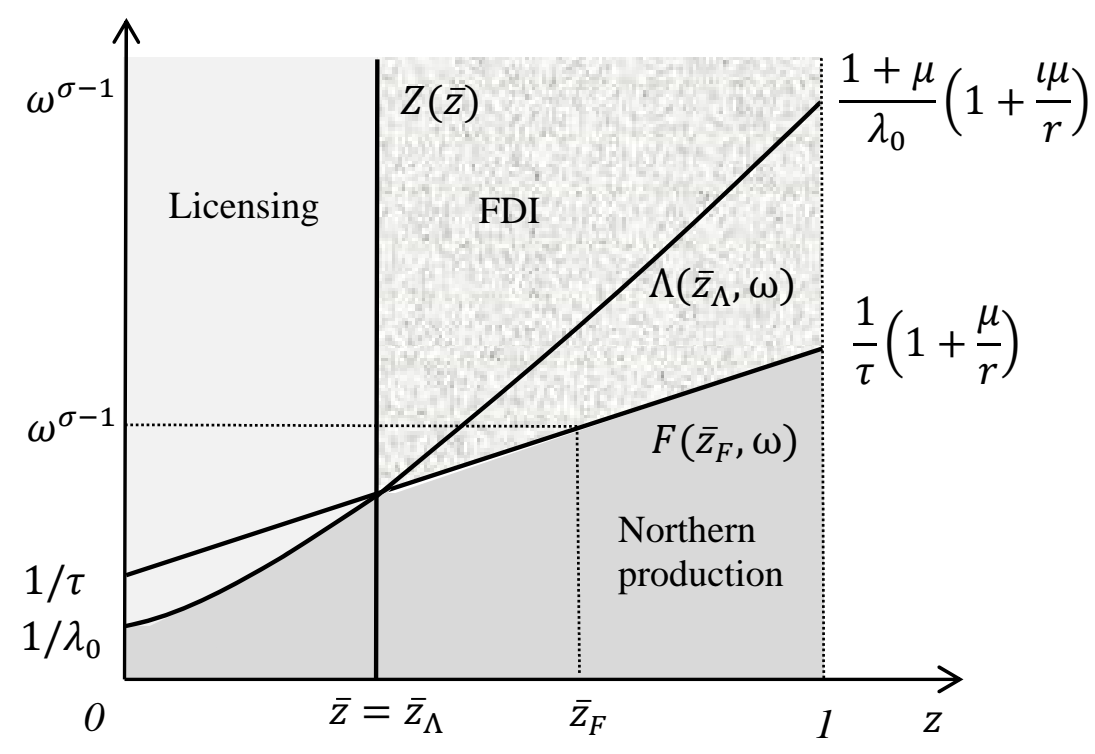

Figure 1: The equalized profit schedules

Figure 1 plots (8)-(10) with $\omega^{\sigma-1}$ on the vertical axes and $z$ on the horizontal axes when all three activities occur in an equilibrium. Along the $F\left(\bar{z}_{F}, \omega\right)$ schedule, $\omega^{\sigma-1}=1 / \tau$ at $z=\bar{z}_{F}=0$ and $\omega^{\sigma-1}=(1 / \tau)(1+\mu / r)$ at $z=\bar{z}_{F}=1$. Along the $\Lambda\left(\bar{z}_{\Lambda}, \omega\right)$ schedule, $\omega^{\sigma-1}=1 / \lambda_{0}$ at $z=\bar{z}_{\Lambda}=0$ and $\omega^{\sigma-1}=\left[(1+\mu) / \lambda_{0}\right](1+\iota \mu / r)$ at $z=\bar{z}_{\Lambda}=1$. Last, the $Z(\bar{z})$ schedule intersects the horizontal axes at $z=\bar{z}$, which solves (10). Depending on the values $\omega$ and $z$ take, three distinct areas arise. First, the dark shaded area defines $(\omega, z)$ such that Northern production is the most profitable mode. In any industry $z$, Northern production is preferred over FDI if the relative Northern wage is below the value of $\omega$ defined for that industry by the $F$ function. Likewise, Northern production is preferred over licensing if the relative Northern wage is below the value of $\omega$ defined for that industry by the $\Lambda$ function. Second, the light shaded area to the left of $\bar{z}$ defines $(\omega, z)$ such that licensing is the most profitable mode. In any industry $z$ in this area, conditions (6) and (7) hold and so, licensing is preferred over Northern production and FDI. Last, the light shaded area to the right of $\bar{z}$ defines the values of $(\omega, z)$ such that FDI is the most profitable mode. In any industry $z$ in this area, condition (5) holds and so, FDI is preferred over Northern production. FDI is also preferred over licensing in industries $z>\bar{z}$.

When all three activities occur in an equilibrium, as depicted in Figure 1, Northern firms license in industries $z<\bar{z}=\bar{z}_{\Lambda}$, engage in FDI in industries $\bar{z}=\bar{z}_{\Lambda}<z<\bar{z}_{F}$, and produce in the North in industries $z>\bar{z}_{F}$. In the next section, we establish the market clearing condition that pins down the equilibrium $\bar{z}_{F}$ and $\omega$. We then establish the equilibrium in Proposition 1 in Section 3.

required for any change in the cut-offs $\bar{z}_{\Lambda}$ and $\bar{z}_{F}$. 


\subsection{Market Clearing}

In equilibrium, labour is fully employed in both regions. Since Northern labor is employed only in industries $\left[\bar{z}_{F}, 1\right]$, the labour market clearing condition for the North is $L=\int_{\bar{z}_{F}}^{1} n(z) y(z) d z$. This condition simplifies to $w L=\gamma\left(1-\bar{z}_{F}\right)\left(E+E^{*}\right)$, since $n(z) y(z)=\gamma\left(E+E^{*}\right) / w$ in the Northern industry $z$.

Aggregate expenditure $E+E^{*}$ equals aggregate income. In the North, $E$ consists of labour income and aggregate profits from all three activities: $E=w L+\Pi^{N}+\Pi^{F}+\Pi^{\Lambda}$. In the South, $E^{*}$ consists of labour income and aggregate profits from licensing and FDI: $E^{*}=w^{*} L^{*}+\Pi^{\Lambda *}+\Pi^{F *}$. Letting $L_{F}^{*}$ and $L_{\Lambda}^{*}$ denote the aggregate Southern labour employed in FDI and licensing industries respectively, we obtain: $\Pi^{N}=(p-w) L, \Pi^{F}+\Pi^{F *}=\left(p_{M}-w^{*}\right) L_{F}^{*}$ and $\Pi^{\Lambda}+\Pi^{\Lambda *}=\left(p_{M}-w^{*}\right) L_{\Lambda}^{*}$. Since $p=w / \gamma$ and $p_{M}=w^{*} / \gamma$, it follows that we must have:

$$
E+E^{*}=\frac{1}{\gamma} w L+w^{*} L^{*}+\frac{1-\gamma}{\gamma} w^{*}\left(L_{F}^{*}+L_{\Lambda}^{*}\right)
$$

The aggregate Southern labour employed in FDI and licensing is $L_{F}^{*}=\int_{\bar{z}}^{\bar{z}_{F}} n(z) y_{M}(z) d z$ and $L_{\Lambda}^{*}=\int_{0}^{\bar{z}} n(z) y_{M}(z) d z$, which simplifies to ${ }^{13}$

$$
L_{F}^{*}=\gamma\left(\frac{E+E^{*}}{w^{*}}\right) I_{F} ; \quad \text { and } \quad L_{\Lambda}^{*}=\gamma\left(\frac{E+E^{*}}{w^{*}}\right) I_{\Lambda}
$$

where

$$
I_{F} \equiv \int_{\bar{z}}^{\bar{z}_{F}} \frac{d z}{1+\gamma^{1-\sigma} \mu z / g} \quad \text { and } \quad I_{\Lambda} \equiv \int_{0}^{\bar{z}} \frac{d z}{1+\gamma^{1-\sigma} \iota \mu z / g}
$$

are the measures of innovated products in FDI and licensing industries respectively.

Using (12)-13), we solve for the aggregate income and then rewrite the labour market clearing condition $w L=\gamma\left(1-\bar{z}_{F}\right)\left(E+E^{*}\right)$ to obtain the market clearing schedule: ${ }^{14}$

$$
H\left(\bar{z}, \bar{z}_{F}, \omega\right) \equiv 1+\frac{\gamma}{\omega} \frac{L^{*}}{L}-\frac{1-(1-\gamma)\left(I_{F}+I_{\Lambda}\right)}{1-\bar{z}_{F}}=0
$$

Lemma Along the $H\left(\bar{z}, \bar{z}_{F}, \omega\right)$ schedule, $d \omega / d \bar{z}_{F}<0$ and $d \omega / d \bar{z}<0$.

\footnotetext{
${ }^{13}$ Since $y_{M}(z)=p_{M}^{-\sigma}\left(E+E^{*}\right) / P^{1-\sigma}(z), P^{1-\sigma}(z)=n(z) p_{M}^{1-\sigma}+n^{*}(z) p^{* 1-\sigma}$, and $\eta(z) \equiv n^{*}(z) / n(z)$ in a Southern industry $z$, we obtain:

$$
L_{F}^{*}=\int_{\bar{z}}^{\bar{z}_{F}} n(z) y_{M}(z) d z=\left(E+E^{*}\right) \int_{\bar{z}}^{\bar{z}_{F}} \frac{p_{M}^{-\sigma} n(z) d z}{n(z) p_{M}^{1-\sigma}+n^{*}(z) p^{* 1-\sigma}}=\gamma\left(\frac{E+E^{*}}{w^{*}}\right) I_{F} .
$$

${ }^{14}$ The aggregate income is $E+E^{*}=\left[w^{*} L^{*}+\gamma^{-1} w L\right] /\left[1-(1-\gamma)\left(I_{F}+I_{\Lambda}\right)\right]$.
} 
Proof: see Appendix.

The $H\left(\bar{z}, \bar{z}_{F}, \omega\right)$ schedule associates with each $\bar{z}_{F}$ and $\bar{z}$ a value of $\omega$ such that labour market clears in both regions. As $\bar{z}_{F}$ rises, Northern firms in a wider range of industries choose FDI over Northern production. The demand for Northern labour declines and so, the relative Northern wage $\omega$ necessarily falls to restore the labour market equilibrium. Hence, $d \omega / d \bar{z}_{F}<0$. As $\bar{z}$ rises, the range of licensing industries expands while the range of FDI industries contracts. The relative demand for Southern labour rises as a result, because the relative number of Southern products within a given industry $z$ is higher under licensing than FDI (since $\iota>1$ ). To eliminate the excess demand, the relative Northern wage $\omega$ falls. Thus, $d \omega / d \bar{z}<0$.

\section{Equilibrium}

Figure 2 shows the equilibrium with all three activities. The equilibrium relative Northern wage $\omega$ is implicitly defined by $H(\omega) \equiv H\left(\bar{z}, \bar{z}_{F}(\omega), \omega\right)=0$, where the equilibrium cut-off industry $\bar{z}_{F}(\omega)$ solves (8).

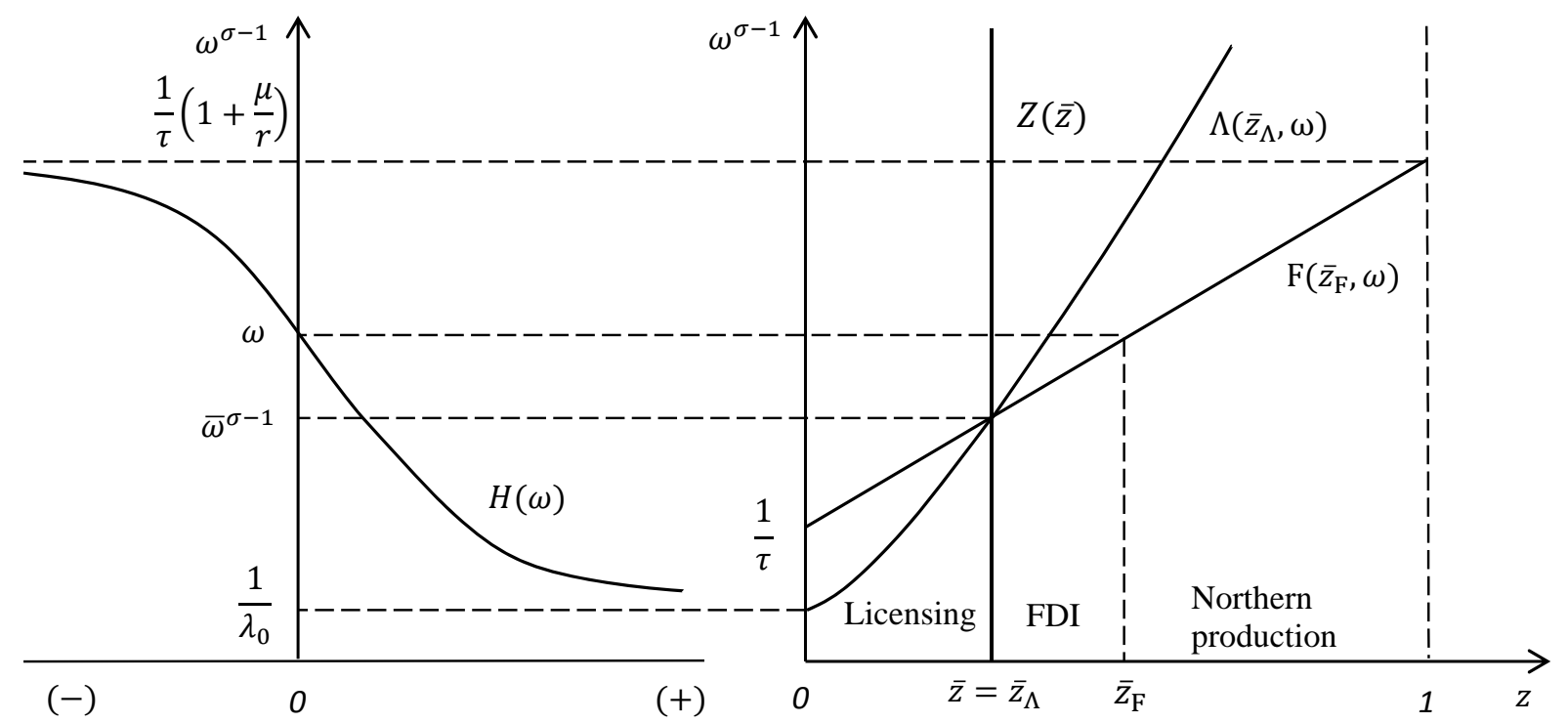

Figure 2: The equilibrium

The $H(\omega)$ schedule is negatively sloped. At any $\omega$ below its equilibrium value, $H(\omega)>0$ and Northern labour is in excess demand, relative to Southern labour. The relative Northern wage $\omega$ has to rise to equilibrate the labour market. As $\omega$ rises, the relative demand for Northern labour falls for two reasons. First, a higher $\omega$ lowers the relative demand for Northern labour on impact: 
$H_{\omega}<0$. Second, a higher $\omega$ increases the profitability of FDI relative to Northern production: $d \bar{z}_{F} / d \omega>0$. As the range of FDI industries widens (i.e. $\bar{z}_{F}$ rises), the relative demand for Northern labour falls: $H_{\bar{z}_{F}}<0$.

The equilibrium relative Northern wage satisfies the following condition:

$$
\frac{1}{\lambda_{0}}<\omega^{\sigma-1}<\frac{1}{\tau}\left(1+\frac{\mu}{r}\right)
$$

If $\omega^{\sigma-1} \leq 1 / \lambda_{0}$, Northern firms in all industries produce in the North; Northern labour is in excess demand and $\omega$ has to rise to clear the labour market. If $\omega^{\sigma-1} \geq(1 / \tau)(1+\mu / r)$, all Northern firms produce in the South; Northern labour is in excess supply and $\omega$ has to fall to clear the labour market.

Proposition 1: There exists a unique interior equilibrium with $0<\bar{z}=\bar{z}_{\Lambda}<\bar{z}_{F}<1$, where Northern firms license in industries $z<\bar{z}=\bar{z}_{\Lambda}$, engage in FDI in industries $\bar{z}=\bar{z}_{\Lambda}<z<\bar{z}_{F}$, and produce in the North in industries $z>\bar{z}_{F}$, provided $\lambda_{0}>\tau$ and the following condition holds:

$$
L^{*} / L>\bar{\omega}\left[\frac{\bar{z}-(1-\gamma) I_{\Lambda}}{\gamma(1-\bar{z})}\right]
$$

Proof: see Appendix.

The condition (17) is necessary for FDI to arise in an equilibrium. This scenario is illustrated in Figure 2, where the equilibrium relative Northern wage $\omega$ is above its critical value $\bar{\omega}$ (which corresponds to the cut-off industry $\bar{z}=\bar{z}_{\Lambda}$ ) and $0<\bar{z}=\bar{z}_{\Lambda}<\bar{z}_{F}<1$. The condition requires a sufficiently large relative size of the Southern market, a low rent share $\lambda_{0}$, a low cost of FDI $(1-\tau)$, a high risk of imitation $\mu / r$, or a high licensing risk premium $\iota$ The cut-offs $\bar{z}$ and $\bar{z}_{F}$ are interior: $\bar{z}>0$ since $\lambda_{0}>\tau$ (i.e., the condition (11)) and $\bar{z}_{F}<1$ since $\omega^{\sigma-1}<(1 / \tau)(1+\mu / r)$ (i.e., the condition (16)). Proposition 1 is consistent with the fact that arms-length licensing by U.S. firms in Southern countries occurs predominantly in industries that produce more complex products and occurs less in industries where imitation risk is relatively greater.

\footnotetext{
${ }^{15}$ This result follows since (i) the right hand side of 17 rises with $\omega$ and $\bar{z}$; (ii) $\bar{z}$ falls with $\iota, \mu / r$ and $\tau$ and rises with $\lambda_{0}$; and (iii) $\bar{\omega}$ falls with $\iota$ and $\tau$, rises with $\lambda_{0}$, and does not change with $\mu / r$.
} 


\section{Strengthening Southern IPR protection}

The impact of Southern IPR protection depends on the mode of technology transfer. It is stronger under licensing than FDI, holding $z$ constant, for two reasons. First, the Northern licensor's rent share in industry $z$ rises with stronger IPRs: $d \lambda(z) / d \mu<0$. Second, because licensing involves the risk premium $\iota>1$, the risk of imitation under licensing falls relatively more: $d m(z) / d \mu=\iota z$ in a licensing industry and $d m(z) / d \mu=z$ in an FDI industry. To highlight each force at play, we examine how strengthening Southern IPR protection impacts technology transfer under three different cases. In Case 1, we assume no imitation risk premium under licensing: $\iota=1$. The terms of the licensing contract induce compliance by the licensee such that licensing is no more risky than FDI. We lift this restriction in Case 2, where we let $\iota>1$ and assume instead that the licensing rent share is constant across industries: $\lambda=\lambda_{0}$. Here, the terms of the licensing contact fail to limit the extra risk of imitation associated with licensing, and the existence of the licensing risk premium provides an internalization motive for FDI. Last in Case 3, we lift both restrictions and let $\lambda=\lambda_{0} /(1+\mu z)$ and $\iota>1$.

\subsection{Case 1}

In this section, we assume that (i) the risk of imitation under licensing and FDI is the same $(\iota=1)$ and (ii) the licensor's rent share decreases with the risk of imitation, i.e., $\lambda=\lambda_{0} /(1+\mu z)$. Stronger IPRs reduce the licensing rent share and this drives the difference in the impact of stronger IPRs between licensing and FDI. Figure 3 shows the impact of strengthening Southern IPRs on equilibrium outcomes.

As $\mu$ falls, the $Z(\bar{z})$ schedule shifts rightward to $Z^{\prime}(\bar{z})$ and the $F\left(\bar{z}_{F}, \omega\right)$ schedule rotates clockwise to $F^{\prime}\left(\bar{z}_{F}, \omega\right)$. The cut-offs $\bar{z}$ and $\bar{z}_{F}$ determining the allocation of Northern production to licensing and FDI both rise, holding $\omega$ constant. The desirability of FDI relative to Northern production increases because the risk of imitation associated with FDI falls. Also, the attractiveness of licensing relative to FDI rises because the Northern licensor's rent share rises when $\lambda=\lambda_{0} /(1+\mu z)$ and $\iota=1$. Within each industry, the relative number of imitated products $\eta(z)=\mu z / g$ falls with limited imitation. A reduction in $\mu$ also reduces the relative demand for Northern labour. To restore the labour market equilibrium, the $H(\omega)$ schedule shifts down to $H^{\prime}(\omega)$ and the relative 


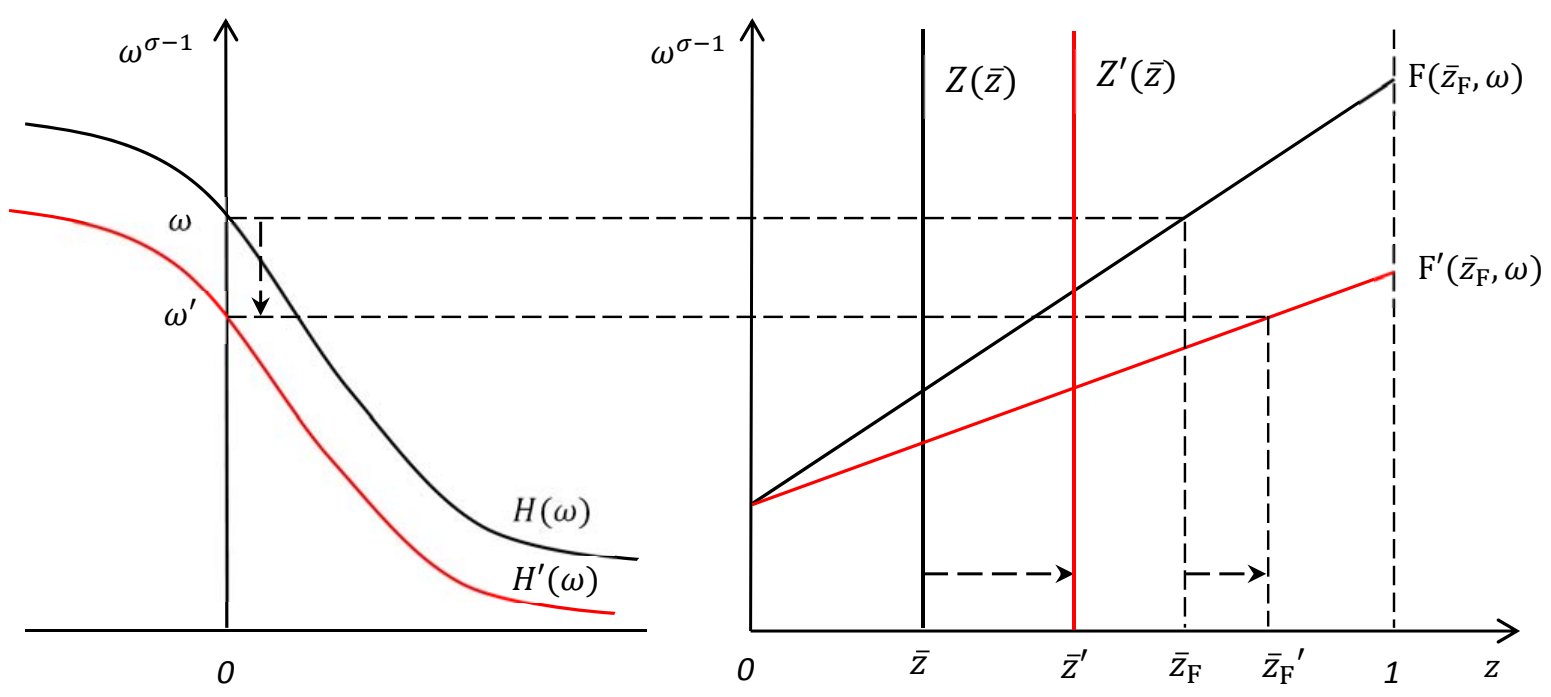

Figure 3: Strengthening IPRs

Northern wage falls to $\omega^{\prime}{ }^{16}$ As $\omega$ falls, the relative attractiveness of Northern production rises and the cut-off $\bar{z}_{F}$ falls along the $F^{\prime}\left(\bar{z}_{F}, \omega\right)$ schedule. The overall impact of stronger IPRs on $\bar{z}_{F}$ is unambiguously positive. Consequently, multinational activity expands across industries, shifting from Northern production to FDI as $\bar{z}_{F}$ rises and away from FDI to licensing as $\bar{z}$ rises. Proposition 2 establishes the result.

Proposition 2: When $\lambda=\lambda_{0} /(1+\mu z)$ and $\iota=1$, a strengthening of IPR protection in the South (i.e., a decline in $\mu$ ) increases the cut-off $\bar{z}$ (that determines the split of multinational production between licensing and FDI) with elasticity one so that the set of industries engaged in licensing expands. The cut-off $\bar{z}_{F}$ (that determines the North-South production split) rises so that the set of industries engaged in multinational activity expands with elasticity less than one.

Proof: see Appendix.

In equilibrium, the cut-off $\bar{z}$ rises with elasticity one due to the direct impact of limited imitation

\footnotetext{
${ }^{16}$ When $\iota=1$, the market clearing schedule 15 simplifies to:

$$
H\left(\bar{z}_{F}, \omega\right) \equiv 1+\frac{\gamma}{\omega} \frac{L^{*}}{L}-\frac{1-(1-\gamma) I}{1-\bar{z}_{F}}=0, \quad \text { where } \quad I \equiv \int_{0}^{\bar{z}_{F}} \frac{d z}{1+\gamma^{1-\sigma} \mu z / g} .
$$

The relative demand for Northern labour falls with limited imitation since $d H / d \mu=H_{\eta} d \eta(z) / d \mu+H_{\bar{z}_{F}} d \bar{z}_{F} / d \mu>0$. First, $H_{\eta}<0$ and $d \eta(z) / d \mu>0$. A decline in imitation reduces the share of imitated products in each industry and therefore increases the relative demand for Northern labour. Second, $H_{\bar{z}_{F}}<0$ and $d \bar{z}_{F} / d \mu<0$ so that $\bar{z}_{F}$ increases, holding $\omega$ constant. FDI expands while Northern production contacts, and the relative demand for Northern labour falls as a result. This second effect dominates so that overall Northern labor demand falls as $\mu$ declines.
} 
on the licensing rent share. A reduction in $\omega$ does not affect $\bar{z}$ since the choice between FDI and licensing is independent of $\omega$. A reduction in $\omega$, however, decreases the profitability of Southern relative to Northern production and so limits the expansion in FDI across industries. Therefore in equilibrium, the cut-off $\bar{z}_{F}$ rises with elasticity less than one.

Note that if imitation risk were constant across industries (as is the case in existing North-South models of FDI and technology transfer) then an increase in licensing activity would be necessarily accompanied by a reduction in FDI. Thus, in traditional models, stronger IPRs cannot increase the volume of licensing without reducing FDI. In our model by contrast, licensing and FDI volumes both rise with stronger IPRs. FDI volume falls in low- $z$ industries (which switch to licensing) but rises in high- $z$ industries (which switch from Northern production). In addition, within each industry, the overall volume of multinational activity rises.

We next examine the impact of stronger IPRs on Southern production. The overall volume of Northern production, which consists of innovated products only, is $Q_{N} \equiv \int_{\bar{z}_{F}}^{1} n(z) y(z) d z=$ $\left(1-\bar{z}_{F}\right)\left(E+E^{*}\right) \gamma / w$. Southern production consists of innovated and imitated products. The overall volume of innovated products in licensing and FDI industries is $Q_{\Lambda}=I_{\Lambda}\left(E+E^{*}\right) \gamma / w^{*}$ and $Q_{F}=I_{F}\left(E+E^{*}\right) \gamma / w^{*}$, where the measures of innovated products $I_{\Lambda}$ and $I_{F}$ are given in (14). It follows that relative to Northern production, the volume of innovated products in licensing and FDI industries is given by:

$$
\frac{Q_{\Lambda}}{Q_{N}}=I_{\Lambda}\left(\frac{\omega}{1-\bar{z}_{F}}\right) \quad \text { and } \quad \frac{Q_{F}}{Q_{N}}=I_{F}\left(\frac{\omega}{1-\bar{z}_{F}}\right) .
$$

The overall volume of imitated products in licensing and FDI industries is $Q_{\Lambda}^{*}=I_{\Lambda}^{*}\left(E+E^{*}\right) / w^{*}$ and $Q_{F}^{*}=I_{F}^{*}\left(E+E^{*}\right) / w^{*}$, where the measures of imitated products are $I_{\Lambda}^{*}=\bar{z}-I_{\Lambda}$ and $I_{F}^{*}=$ $\bar{z}_{F}-\bar{z}-I_{F}{ }^{17}$ Thus, the relative volume of imitated products is

$$
\frac{Q_{\Lambda}^{*}}{Q_{N}}=\frac{I_{\Lambda}^{*}}{\gamma}\left(\frac{\omega}{1-\bar{z}_{F}}\right) \quad \text { and } \quad \frac{Q_{F}^{*}}{Q_{N}}=\frac{I_{F}^{*}}{\gamma}\left(\frac{\omega}{1-\bar{z}_{F}}\right) .
$$

An increase in IPR protection in the South has two effects on technology transfer. First is the within-industry shift from imitative to innovative production. This occurs as the share of imitated products within each industry $z$ in the South, $\eta(z)$, falls and production reallocates from Southern imitators to multinational firms. Second is the cross-industry shift. The relative profitability of Northern production falls and so, FDI activity expands across industries (i.e. $\bar{z}_{F}$ rises). New

\footnotetext{
${ }^{17}$ The result follows since $Q_{\Lambda}^{*} \equiv \int_{0}^{\bar{z}} n^{*}(z) y^{*}(z) d z$ and $Q_{F}^{*} \equiv \int_{\bar{z}}^{\bar{z}_{F}} n^{*}(z) y^{*}(z) d z$, where $y^{*}(z)=p^{*-\sigma}(E+$ $\left.E^{*}\right) / P^{1-\sigma}(z), P^{1-\sigma}(z)=n(z) p_{M}^{1-\sigma}+n^{*}(z) p^{* 1-\sigma}$, and $\eta(z)=n^{*}(z) / n(z)$.
} 
industries are established in the South as production reallocates from the North. Also, since the relative profitability of licensing rises, licensing activity expands across industries (i.e. $\bar{z}$ rises) and the composition of multinational activity shifts from FDI to licensing.

How does strengthening Southern IPRs affect market-based technology transfer to the South? Proposition 3 addresses this question:

Proposition 3: Suppose IPR protection in the South becomes stronger (i.e., $\mu$ declines). When $\lambda=\lambda_{0} /(1+\mu z)$ and $\iota=1$, both the volume of overall multinational production relative to Northern production $\left(Q_{\Lambda}+Q_{F}\right) / Q_{N}$ and the ratio of licensed production $\left(Q_{\Lambda} / Q_{N}\right)$ to Northern production expand unambiguously. Furthermore, the ratio of FDI production relative to Northern production $\left(Q_{F} / Q_{N}\right)$ also rises provided the rent share of licensors $\lambda_{0}$ is sufficiently low.

Proof: see Appendix.

Proposition 3 states that relative to Northern production, Southern production of innovated products rises unambiguously under licensing when Southern IPRs are strengthened while under FDI, it rises provided the licensor's rent share $\lambda_{0}$ is low. Three effects determine the impact: a reduction in the relative Northern wage $\omega$; an increase in the cut-off $\bar{z}_{F}$; and an increase in the measures of innovated products $I_{\Lambda}$ and $I_{F}$. Both $Q_{\Lambda} / Q_{N}$ and $Q_{F} / Q_{N}$ fall as $\omega$ falls and rise as $\bar{z}_{F}$ rises. Also, both $Q_{\Lambda} / Q_{N}$ and $Q_{F} / Q_{N}$ rise as $I_{\Lambda}$ and $I_{F}$ rise. This last effect is crucial in determining the overall impact, and explains the difference in the impact on licensing and FDI. In licensing industries, $I_{\Lambda}$ rises with elasticity one as $\mu$ falls. This causes a strong positive impact on $Q_{\Lambda} / Q_{N}$ and so $Q_{\Lambda} / Q_{N}$ rises with stronger IPRs. In FDI industries, by contrast, $I_{F}$ does not rise much and may even fall. The impact of stronger IPRs on $Q_{F} / Q_{N}$ is thus ambiguous and depends on $\lambda_{0}$.

The size of the rent share parameter $\lambda_{0}$ determines the relative strength of the above three effects. When $\lambda_{0}$ is low, the cut-off $\bar{z}$ determining the extent of licensing activity is low. As stronger IPRs increase $\bar{z}$ from a low level with elasticity one, the relative demand for Northern labour falls only little. Thus, $\omega$ falls only little and so the negative impact of a reduction in $\omega$ on $\bar{z}_{F}$ is limited 18 Consequently, an increase in $I_{F}$ is large and the resulting positive impact on $Q_{F} / Q_{N}$ is strong.

The impact of stronger IPRs in the South on the market-based transfer of technology is particularly strong for licensing. Licensed production of innovated products rises relatively more (in elasticity terms) than FDI production. This is because licensing activity expands greatly across

\footnotetext{
${ }^{18}$ The royalty rate $\lambda_{0}$ does not affect $\bar{z}_{F}$ directly, only indirectly through its impact on $\omega$.
} 
industries while FDI activity does not expand that much and may even contract. The range of FDI industries shrinks due to a shift of multinational activity towards licensing and does not expand much with production reallocation from the North, because the cost of Southern labour rises. Since the expansion in licensing activity is relatively strong, $I_{\Lambda}$ rises more than does $I_{F}$ and so, $Q_{\Lambda} / Q_{N}$ rises more than $Q_{F} / Q_{N}$.

We now examine the impact of Southern IPR protection on technology transfer through imitation. The distinction between licensing and FDI industries is critical for the result. We can show:

Proposition 4: When $\lambda=\lambda_{0} /(1+\mu z)$ and $\iota=1$, stronger IPR protection in the South lowers the volume of imitated production relative to Northern production $\left(Q_{\Lambda}^{*}+Q_{F}^{*}\right) / Q_{N}$. While the volume of imitated production derived from FDI declines relative to Northern production, that derived from licensing rises. Finally, the volume of FDI production relative to imitated production derived from FDI $\left(Q_{F} / Q_{F}^{*}\right)$ rises if the rent share of licensors $\lambda_{0}$ is sufficiently low.

Proof: see Appendix.

The results established in Proposition 4 depend critically on the change in the measures of imitated products under licensing and FDI, $I_{\Lambda}^{*}$ and $I_{F}^{*}$. These measures respond to both the within and cross-industry shift of production, and the relative strength of these two shifts determines the overall impact. In licensing industries, the within-industry shift is weak, since imitation in these industries is low to begin with. Thus, the reduction in imitative production within each industry is small and the negative impact of this reduction on $I_{\Lambda}^{*}$ is weak. At the same time, the crossindustry expansion in licensing is strong. The expansion increases the scope for imitation, and this increases $I_{\Lambda}^{*}$. This latter effect dominates and so, $I_{\Lambda}^{*}$ rises overall, causing $Q_{\Lambda}^{*} / Q_{N}$ to rise with stronger IPRs. FDI industries are different since their technological complexity is lower relative to licensing industries. Here, the within-industry shift is strong, because imitation is reduced to a greater degree by stronger IPRs. At the same time, the cross-industry expansion is weak. Thus,

the measure $I_{F}^{*}$ falls overall, causing $Q_{F}^{*} / Q_{N}$ to fall as well. The reduction in $Q_{F}^{*} / Q_{N}$ more than offsets the increase in $Q_{\Lambda}^{*} / Q_{N}$ so that the volume of imitated production $\left(Q_{\Lambda}^{*}+Q_{F}^{*}\right) / Q_{N}$ falls.

\subsection{Case 2}

In this section, we assume the rent share is unaffected by Southern IPR protection (i.e. $\lambda=\lambda_{0}$ ) and the risk of imitation under licensing exceeds that under FDI (i.e. $\iota>1$ ). Proposition 2, which establishes the impact of IPRs on the cut-offs $\bar{z}$ and $\bar{z}_{F}$, now changes to: 
Proposition 2b: When $\lambda=\lambda_{0}$ and $\iota>1$, stronger IPR protection in the South increases the cut-off $\bar{z}$ with elasticity one. The cut-off $\bar{z}_{F}$ also rises, provided the licensing risk premium is not too large (i.e. $\iota \leq 2$ ).

Proof: see Appendix.

The impact of stronger IPRs on the cut-off $\bar{z}$ is as before: $\bar{z}$ rises with elasticity one, but now due to the direct impact of limited imitation risk. The impact on the cut-off $\bar{z}_{F}$, by contrast, is ambiguous in this case: $\bar{z}_{F}$ rises less and may fall with stronger IPRs, depending on the licensing risk premium $\iota$. This is because when $\iota>1$, a reduction in the relative Northern wage $\omega$, which limits an expansion in FDI, is more pronounced. Labour demand rises in the South and falls in the North for two reasons now: (i) as $\bar{z}_{F}$ rises and FDI activity expands and (ii) as $\bar{z}$ rises and licensing activity expands across industries. The expansion in licensing activity impacts labour demand when $\iota>1$, since the relative number of imitated products is highest in licensing in this case: $\eta(z)=\iota \mu z / g$ for $z \in(0, \bar{z}]$ and $\eta(z)=\mu z / g$ for $z \in\left(\bar{z}, \bar{z}_{F}\right]$.

Proposition $2 \mathrm{~b}$ states that $\iota \leq 2$ is sufficient for $\bar{z}_{F}$ to rise with stronger Southern IPR protection. When the licensing risk premium $\iota$ is low, the relative Northern wage $\omega$ falls only little as $\bar{z}$ rises. Consequently, the wage effect of stronger IPRs on FDI is weak: a reduction in $\omega$ limits the expansion in FDI but does not fully offset it.

Assuming $\iota \leq 2$, Propositions 3 and 4 continue to summarize the impact of stronger Southern IPRs on technology transfer to the South. Proposition 5 establishes this result.

Proposition 5: When $\lambda=\lambda_{0}$ and $1 \leq \iota \leq 2$, the results established in Propositions 3 and 4 continue to hold.

Proof: see Appendix.

\subsection{Case 3}

We now relax the assumption of the rent share being constant while also allowing risk of imitation to be higher under licensing relative to FDI (i.e. $\iota>1$ ). This case is more general than Case 2 in that the rent share of licensors also responds to strengthening Southern IPRs. This generalization, however, has no impact on our results: Propositions $2 \mathrm{~b}$ and 5 apply here as well.

Proposition 6: When $\lambda=\lambda_{0} /(1+\mu z)$ and $\iota>1$, the results established in Propositions $2 b$ and 5 continue to hold. 
Proof: see Appendix.

\section{$5 \quad$ Empirical Implications}

Empirical evidence supporting the predictions of the theoretical model developed in this paper is provided in our companion paper Ivus et al. (2015). Using a large data-set of U.S. parent companies from the manufacturing sector, in Ivus et al. (2015) we study how intra-firm and arm's length technology transfers undertaken by these firms respond to patent reforms in developing countries. Following the theoretical analysis of the present paper, in Ivus et al. (2015) we examine the impact of patent reforms by type of industry: complex and discrete. As predicted by our theoretical model, we find that firms in discrete product industries are indeed more sensitive to patent reforms than those in complex product industries. Patent reforms enable local firms to attract more arms-length technology transfer, especially of discrete products which are relatively easier to imitate.

Table 1 provides a sample of the findings of Ivus et al. (2015). This table summarizes how the composition of technology transfer responds as the strength of patent protection increases in the developing world. The table presents two measures of this composition: first, the ratio of armslength licensing to affiliated licensing (i.e., licensing by the parent firm to an affiliate or subsidiary in the host country); second, the ratio of arms-length licensing to affiliate sales. These measures are derived for 12 of the leading developing countries in the sample (such as South Korea, China, India, and Brazil) and the table shows the median ratios across those countries. It is apparent that the ratios are much larger for complex industries relative to discrete ones. This finding confirms a key insight underlying the theoretical model developed in this paper-i.e., that firms in complex industries have a higher propensity to engage in arms-length licensing due to their products being more difficult to imitate. Table 1 further shows that post-patent reform is associated with a greater increase in the arms-length licensing of firms in the discrete industries. For example, patent reform is associated with a 71 percent increase in the ratio of arms-length to affiliated licensing in discrete industries and a 30 percent in complex industries. Likewise, patent reform is associated with a more than doubling of the ratio of arms-length licensing to affiliate sales in the discrete industries and a 13 percent growth in the same ratio for the complex industries. Again, this finding is consistent with our model's prediction that firms in discrete industries are expected to benefit more from stronger patent protection since their products are easier to imitate. 
Table 1: Patent Law Reforms and Technology Transfers via FDI and Arms-Length Transactions

\begin{tabular}{lcccc}
\hline & \multicolumn{2}{l}{$\begin{array}{l}\text { Ratio of Arms-Length Licensing } \\
\text { to Intra-Firm Licensing }\end{array}$} & \multicolumn{2}{l}{$\begin{array}{l}\text { Ratio of Arms-Length Licensing } \\
\text { to Affiliate Sales (x 1000) }\end{array}$} \\
Industries: & Discrete & Complex & Discrete & Complex \\
\hline Pre-Reform & 0.053 & 0.433 & 0.250 & 2.110 \\
Post-Reform & 0.091 & 0.564 & 0.510 & 2.400 \\
\% Change & $71 \%$ & $30 \%$ & $106 \%$ & $13 \%$ \\
\hline
\end{tabular}

Notes: The ratios are median values across 12 developing countries over the 1992-2009 period: Argentina, Brazil, Chile, China, Hong Kong, India, Mexico, Philippines, Singapore, South Africa, South Korea, and Venezuela. Year of patent reform varies by country. Source: Ivus et al. (2015).

\section{Conclusion}

This paper examines the effects of stronger IPR protection in developing countries on international technology transfer to their economies. Like much of the literature on the subject, we have found it useful to adopt a stylized North-South paradigm where innovation is concentrated in the North and imitation in the South. However, by allowing imitation risk (or the South's ability to reverseengineer) to vary across industries, we depart from existing literature in an important dimension. In our view, such industry level variation in imitation risk is intuitively plausible and empirically relevant: most observers would agree that imitation costs are quite low for certain industries (such as pharmaceuticals) relative to others (such as transport equipment). We capture such industry level variation in imitation risk by a single parameter that serves as a proxy for the technological sophistication of an industry's products - a feature that is inversely related to the ease of imitation.

In the model, Northern innovators in each industry decide whether or not to shift production to the South as well as whether to license their technologies to local Southern firms or establish wholly owned subsidiaries by undertaking FDI. In equilibrium, Northern firms tend to use technology licensing in industries that face the lowest risk of imitation whereas they refrain from any type of multinational activity in industries where such risk is high, preferring instead to produce in the North where their intellectual property is secure. Interestingly, North-South FDI occurs in industries where the risk of imitation is of intermediate magnitude.

The model shows that overall multinational activity in the South expands with a strengthening of Southern IPR protection. Furthermore, the extent of technology licensing responds more to this policy change than does FDI. Indeed, while the range of industries over which licensing serves as the channel of technology transfer necessarily increases, the set of industries in which FDI 
plays this role does not necessarily expand and can even shrink. This suggests that North-South models that ignore licensing may overstate the impact of Southern IPR reform on FDI since they do not account for the substitution from internalized technology transfer via FDI to arms length technology transfer via licensing.

A long-standing empirical observation in the literature has been that the internalization decisions of multinationals vary by industry. Our paper helps inform future work in the area by providing a model that puts this empirical finding at center stage and by deriving new results regarding the impact of stronger intellectual property rights on the volume and mode of international technology transfer. 


\section{Appendix}

\section{PROOF OF LEMMA}

The $H\left(\bar{z}, \bar{z}_{F}, \omega\right)$ schedule is given by:

$$
H\left(\bar{z}, \bar{z}_{F}, \omega\right) \equiv 1+\frac{\gamma}{\omega} \frac{L^{*}}{L}-\frac{1-(1-\gamma) I}{1-\bar{z}_{F}}=0
$$

where $I=I_{\Lambda}+I_{F}, I_{\Lambda}=\int_{0}^{\bar{z}} k_{\Lambda}(z) d z, I_{F}=\int_{\bar{z}}^{\bar{z}_{F}} k_{F}(z) d z, k_{\Lambda}(z) \equiv[1+\iota q z]^{-1}, k_{F}(z) \equiv[1+q z]^{-1}$, and $q \equiv \gamma^{1-\sigma} \mu / g$.

It is required to show that $d \omega / d \bar{z}_{F}<0$ and $d \omega / d \bar{z}<0$. By the implicit function theorem, $d \omega / d \bar{z}_{F}=-H_{\bar{z}_{F}} / H_{\omega}$ and $d \omega / d \bar{z}=-H_{\bar{z}} / H_{\omega}$, where from (A1):

$$
\begin{gathered}
H_{\omega}=-\frac{\gamma}{\omega^{2}} \frac{L^{*}}{L}<0 \\
H_{\bar{z}}=\frac{1-\gamma}{1-\bar{z}_{F}}\left[k_{\Lambda}(\bar{z})-k_{F}(\bar{z})\right]<0, \quad \text { since } \quad k_{\Lambda}(\bar{z})<k_{F}(\bar{z}) ; \\
H_{\bar{z}_{F}}=\frac{1}{1-\bar{z}_{F}}\left[(1-\gamma) k_{F}\left(\bar{z}_{F}\right)-\frac{1-(1-\gamma) I}{1-\bar{z}_{F}}\right]<0,
\end{gathered}
$$

since $(1-\gamma) k_{F}\left(\bar{z}_{F}\right)<1$ and $[1-(1-\gamma) I] /\left[1-\bar{z}_{F}\right]=1+\gamma L^{*} /(\omega L)>1$ from A1. As a result, $d \omega / d \bar{z}_{F}<0$ and $d \omega / d \bar{z}<0$.

\section{PROOF OF PROPOSITION 1}

It is required to show that there exists a unique interior equilibrium with $0<\bar{z}=\bar{z}_{\Lambda}<\bar{z}_{F}<1$ provided $\lambda_{0}>\tau$ and the following condition holds:

$$
L^{*} / L>\bar{\omega}\left[\frac{\bar{z}-(1-\gamma) I_{\Lambda}}{\gamma(1-\bar{z})}\right]
$$

The equalized profits schedules are given by:

$$
\begin{gathered}
F\left(\bar{z}_{F}, \omega\right) \equiv \tau \omega^{\sigma-1}-1-\frac{\mu \bar{z}_{F}}{r}=0 \\
\Lambda\left(\bar{z}_{\Lambda}, \omega\right) \equiv\left(\frac{\lambda_{0}}{1+\mu \bar{z}_{\Lambda}}\right) \omega^{\sigma-1}-1-\frac{\iota \mu \bar{z}_{\Lambda}}{r}=0
\end{gathered}
$$




$$
Z(\bar{z}) \equiv \frac{1}{\tau}\left(\frac{\lambda_{0}}{1+\mu \bar{z}}\right)-\frac{r+\iota \mu \bar{z}}{r+\mu \bar{z}}=0
$$

First, we show that the condition A5 ensures that $\omega>\bar{\omega}$ and so $\bar{z}<\bar{z}_{F}$. The relative Northern wage is above its critical value $\bar{\omega}$ (which corresponds to the cut-off industry $\bar{z}=\bar{z}_{\Lambda}$ ) if $H(\omega)>0$ at $\omega=\bar{\omega}$. This follows because $H_{\omega}<0$, which results from A1]:

$$
\frac{d H(\omega)}{d \omega}=H_{\omega}+H_{\bar{z}_{F}} \frac{d \bar{z}_{F}}{d \omega}<0
$$

since $H_{\omega}<0, H_{\bar{z}_{F}}<0, d \bar{z}_{F} / d \omega>0$, and $d \bar{z} / d \omega=0$ from (A2), A4), A6 , and A8 respectively. If $\omega=\bar{\omega}$, then $\bar{z}=\bar{z}_{F}$ and from (A1), $H(\omega=\bar{\omega})>0$ provided the condition (A5) holds. If (A5) does not hold, then $\omega<\bar{\omega}$ and $\bar{z}_{\Lambda}<\bar{z}$. FDI will not arise in this equilibrium (Northern firms will license in industries $z<\bar{z}_{\Lambda}$ and produce in the North in industries $z>\bar{z}_{\Lambda}$ ).

Second, we show that $\bar{z}=\bar{z}_{\Lambda}$ in an equilibrium with FDI. The cut-off $\bar{z}_{\Lambda}$ cannot be below $\bar{z}$; otherwise, the equilibrium will not contain FDI. The cut-off $\bar{z}_{\Lambda}$ also cannot exceed $\bar{z}$. If $\bar{z}<\bar{z}_{\Lambda}<\bar{z}_{F}$, then FDI is the most profitable mode in industries $z \in\left(\bar{z}, \bar{z}_{F}\right)$ and so $\bar{z}_{\Lambda}$ is not a cut-off industry. If $\bar{z}<\bar{z}_{F}<\bar{z}_{\Lambda}$, then the following must be true in industries $z \in\left(\bar{z}_{F}, \bar{z}_{\Lambda}\right)$ : (i) licensing is preferred over Northern production; (ii) Northern production is preferred over FDI; and (iii) FDI is preferred over licensing,- - which is inconsistent and so it not true.

Third, we show that the cut-offs $\bar{z}$ and $\bar{z}_{F}$ are interior. First from (A8), $\bar{z}>0$ provided $\lambda_{0}>\tau$. Next from (A6), $\bar{z}_{F}<1$ since $\omega^{\sigma-1}<(1 / \tau)(1+\mu / r)$ (as discussed in the paragraph below). Thus when $\lambda_{0}>\tau$ and A5 holds, we have: $0<\bar{z}<\bar{z}_{F}<1$.

Fourth, we show that a unique equilibrium with FDI (where $0<\bar{z}=\bar{z}_{\Lambda}<\bar{z}_{F}<1$ ) exists. We evaluate how the $H(\omega) \equiv H\left(\bar{z}, \bar{z}_{F}, \omega\right)$ changes with $\omega$. The $F\left(\bar{z}_{F}, \omega\right)$ and $\Lambda\left(\bar{z}_{\Lambda}, \omega\right)$ schedules associate $\omega$ with $\bar{z}_{F}$ and $\bar{z}_{\Lambda}$. If $\omega^{\sigma-1} \rightarrow 1 / \lambda_{0}$, then $\bar{z}=\bar{z}_{\Lambda} \rightarrow 0$ (follows from (A7)) and $\bar{z}_{F} \rightarrow 0$ (follows from A6 since $\lambda_{0}>\tau$ and $\bar{z}=\bar{z}_{\Lambda}<\bar{z}_{F}$ ). It thus follows from (A1) that $H(\omega) \rightarrow \infty$ as $\omega^{\sigma-1} \rightarrow 1 / \lambda_{0}$. Next if $\omega^{\sigma-1} \rightarrow(1 / \tau)(1+\mu / r)$, then $\bar{z}_{F} \rightarrow 1$ (follows from (A6)) and so from (A1), $H(\omega) \rightarrow-\infty$. Further, $H(\omega)$ is monotonically decreasing in $\omega$. Since $H(\omega)$ approaches plus infinity as $\omega^{\sigma-1} \rightarrow 1 / \lambda_{0}$, minus infinity as $\omega^{\sigma-1} \rightarrow(1 / \tau)(1+\mu / r)$, and is monotonically decreasing in $\omega$, there exists a unique $\omega \in\left(\lambda_{0},(1 / \tau)(1+\mu / r)\right)$ such that $H(\omega)=0$. Given a unique $\omega, \bar{z}=\bar{z}_{\Lambda}$ and $\bar{z}_{F}$ are also unique. In other words, a unique interior equilibrium with FDI exists provided $\lambda_{0}>\tau$ and A5 holds.

\section{PROOF OF PROPOSITION 2}

Assume $\iota=1$. It is required to show that $d \bar{z} / d \mu<0$ and $d \bar{z}_{F} / d \mu<0$. 
First, we show that $d \bar{z} / d \mu<0$. Setting $\iota=1$, we rewrite A8 as follows:

$$
Z(\bar{z}) \equiv \frac{1}{\tau}\left(\frac{\lambda_{0}}{1+\mu \bar{z}}\right)-1=0
$$

By the implicit function theorem, $d \bar{z} / d \mu=-Z_{\mu} / Z_{\bar{z}}$. Since $Z_{\mu}<0$ and $Z_{\bar{z}}<0$ from A10, it follows that $d \bar{z} / d \mu<0$.

Second, we show that $d \omega / d \mu>0$. When $\iota=1$, the $H\left(\bar{z}, \bar{z}_{F}, \omega\right)$ schedule is given by A1 where $I=\int_{0}^{\bar{z}_{F}} k(z) d z$ with $k(z) \equiv[1+q z]^{-1}$ and $q \equiv \gamma^{1-\sigma} \mu / g$. It is useful to rewrite $I$ as follows: $I=q^{-1} \ln \left(1+q \bar{z}_{F}\right)$. By the implicit function theorem:

$$
\frac{d \omega}{d \mu}=-\frac{d H / d \mu}{d H / d \omega}
$$

where $d H / d \omega<0$ from (A9). If follows that $d \omega / d \mu>0$ if $d H / d \mu>0$. Differentiating $H$ with respect to $\mu$, we obtain:

$$
\frac{d H}{d \mu}=H_{\mu}+H_{\bar{z}_{F}} \frac{d \bar{z}_{F}}{d \mu}
$$

where $H_{\bar{z}_{F}}$ is in $\mathrm{A} 4, d \bar{z}_{F} / d \mu=-\bar{z}_{F} / \mu$, and

$$
H_{\mu}=I_{\mu}\left(\frac{1-\gamma}{1-\bar{z}_{F}}\right)=\frac{\bar{z}_{F} k\left(\bar{z}_{F}\right)-I}{\mu}\left(\frac{1-\gamma}{1-\bar{z}_{F}}\right) .
$$

It follows that

$$
\frac{d H}{d \mu}=\frac{\bar{z}_{F}-(1-\gamma) I}{\mu\left[1-\bar{z}_{F}\right]^{2}}>0
$$

since $\bar{z}_{F}-(1-\gamma) I=\left(1-\bar{z}_{F}\right) \gamma L^{*} /(\omega L)$ from A1). Since $d H / d \omega<0$ and $d H / d \mu>0$, we have $d \omega / d \mu>0$.

Last, we show that $d \bar{z}_{F} / d \mu<0$. From $(\mathrm{A} 6)$, we have:

$$
\bar{z}_{F}=\frac{r}{\mu}\left(\tau \omega^{\sigma-1}-1\right) .
$$

Totally differentiating A14 with respect to $\mu$, we obtain:

$$
\frac{d \bar{z}_{F}}{d \mu}=-\frac{\bar{z}_{F}}{\mu}+\frac{d \bar{z}_{F}}{d \omega} \frac{d \omega}{d \mu}=-\frac{\bar{z}_{F}}{\mu}+\frac{d \bar{z}_{F}}{d \omega}\left(-\frac{d H / d \mu}{d H / d \omega}\right) .
$$


It follows that $d \bar{z}_{F} / d \mu<0$ provided the following inequality holds:

$$
\left(-\omega \frac{d H}{d \omega}\right)>\left(\frac{\omega}{\bar{z}_{F}} \frac{d \bar{z}_{F}}{d \omega}\right)\left(\mu \frac{d H}{d \mu}\right)
$$

Using (A13) and (A9), where $H_{\omega}$ and $H_{\bar{z}_{F}}$ are given by (A2) and (A4), we rewrite this inequality as follows:

$$
\frac{\gamma}{\omega} \frac{L^{*}}{L}-\frac{\omega}{1-\bar{z}_{F}} \frac{d \bar{z}_{F}}{d \omega}\left[(1-\gamma) k_{F}\left(\bar{z}_{F}\right)-\frac{1-(1-\gamma) I}{1-\bar{z}_{F}}\right]>\left(\frac{\omega}{\bar{z}_{F}} \frac{d \bar{z}_{F}}{d \omega}\right) \frac{\bar{z}_{F}-(1-\gamma) I}{\mu\left[1-\bar{z}_{F}\right]^{2}} .
$$

Next multiplying both sides by $\left(1-\bar{z}_{F}\right)$ and simplifying, we obtain:

$$
\left(1-\bar{z}_{F}\right) \frac{\gamma}{\omega} \frac{L^{*}}{L}>\left(\frac{\omega}{\bar{z}_{F}} \frac{d \bar{z}_{F}}{d \omega}\right)(1-\gamma)\left(\bar{z}_{F} k_{F}\left(\bar{z}_{F}\right)-I\right) .
$$

Last, using $\left(1-\bar{z}_{F}\right) \gamma L^{*} /(\omega L)=\bar{z}_{F}-(1-\gamma) I$ from $(\mathrm{A} 1), \omega d \bar{z}_{F} /\left(\bar{z}_{F} d \omega\right)=(\sigma-1) \tau \omega^{\sigma-1} r /\left(\mu \bar{z}_{F}\right)$ from A14, and $1-\gamma=1 / \sigma$ and rearranging, we simplify the inequality to obtain $A>B$, where

$$
A \equiv \frac{1}{\sigma-1} \frac{1}{\tau \omega^{\sigma-1}} \frac{\mu \bar{z}_{F}}{r} \quad \text { and } \quad B \equiv \frac{\bar{z}_{F} k\left(\bar{z}_{F}\right)-I}{\sigma \bar{z}_{F}-I}
$$

$A>0$ and $B<0$ since $\bar{z}_{F} k\left(\bar{z}_{F}\right)<I<\sigma \bar{z}_{F}$. Thus A16 holds and $d \bar{z}_{F} / d \mu<0$.

\section{PROOF OF PROPOSITION 3}

Assume $\iota=1$. Let $\tilde{Q}_{\Lambda} \equiv Q_{\Lambda} / Q_{N}=\omega I_{\Lambda} /\left(1-\bar{z}_{F}\right), \tilde{Q}_{F} \equiv Q_{F} / Q_{N}=\omega I_{F} /\left(1-\bar{z}_{F}\right)$, and $\tilde{Q}=\tilde{Q}_{\Lambda}+\tilde{Q}_{F}$, where $I_{\Lambda}=\int_{0}^{\bar{z}}[1+q z]^{-1} d z=q^{-1} \ln (1+q \bar{z}), I_{F}=\int_{\bar{z}}^{\bar{z}_{F}}[1+q z]^{-1} d z=q^{-1} \ln \left[\left(1+q \bar{z}_{F}\right) /(1+q \bar{z})\right]$, and $I=I_{\Lambda}+I_{F}$. It is required to show that $d \tilde{Q} / d \mu<0, d \tilde{Q}_{\Lambda} / d \mu<0$, and $d \tilde{Q}_{F} / d \mu<0$ provided $\lambda_{0}$ is sufficiently low.

First, we show that $d \tilde{Q}_{\Lambda} / d \mu<0$ or the following is true:

$$
\frac{d \tilde{Q}_{\Lambda}}{d \mu} \frac{\mu}{\tilde{Q}_{\Lambda}}=\frac{\mu}{\omega} \frac{d \omega}{d \mu}+\frac{\mu}{1-\bar{z}_{F}} \frac{d \bar{z}_{F}}{d \mu}+\frac{d I_{\Lambda}}{d \mu} \frac{\mu}{I_{\Lambda}}<0
$$

Using A11), A15 and $d I_{\Lambda} / d \mu=-I_{\Lambda} / \mu$, we rewrite (A18) as follows:

$$
\left(-\omega \frac{d H}{d \omega}\right)>\left[1-\bar{z}_{F}+\omega \frac{d \bar{z}_{F}}{d \omega}\right]\left(\mu \frac{d H}{d \mu}\right)
$$

Following the same steps as in proving that A16 holds, we find that A19 holds since $k_{F}\left(\bar{z}_{F}\right)<\sigma$. 
Second, we show that $d \tilde{Q}_{F} / d \mu<0$ or the following is true:

$$
\frac{d \tilde{Q}_{F}}{d \mu} \frac{\mu}{\tilde{Q}_{F}}=\frac{\mu}{\omega} \frac{d \omega}{d \mu}+\frac{\mu}{1-\bar{z}_{F}} \frac{d \bar{z}_{F}}{d \mu}+\frac{d I_{F}}{d \mu} \frac{\mu}{I_{F}}<0
$$

Using (A11), A15 and

$$
\frac{d I_{F}}{d \mu} \frac{\mu}{I_{F}}=-1+k_{F}\left(\bar{z}_{F}\right) \frac{\bar{z}_{F}}{I_{F}}\left[1+\frac{d \bar{z}_{F}}{d \mu} \frac{\mu}{\bar{z}_{F}}\right]
$$

we rewrite $\mathrm{A} 20$ as follows:

$$
\left(-\omega \frac{d H}{d \omega}\right)>\left(1-\bar{z}_{F}\right)\left[1+\omega \frac{d \bar{z}_{F}}{d \omega}\left(\frac{1}{1-\bar{z}_{F}}+\frac{k_{F}\left(\bar{z}_{F}\right)}{I_{F}}\right)\right]\left(\mu \frac{d H}{d \mu}\right)
$$

which following the same steps as in proving that A16 holds, we simplify to:

$$
I_{F}>\bar{z}_{F} k_{F}\left(\bar{z}_{F}\right)-(1-\gamma) k_{F}\left(\bar{z}_{F}\right) I_{\Lambda}
$$

This inequality holds under the following sufficient condition:

$$
G \equiv \ln \left[\frac{1+q \bar{z}_{F}}{1+q \bar{z}}\right]-\frac{q \bar{z}_{F}}{1+q \bar{z}_{F}}>0
$$

$G>0$ when $\lambda_{0}$ is low for three reasons: (i) when $\lambda_{0}$ is at its maximum, $\bar{z}_{F}=\bar{z}$ and $G<0$; (ii) when $\lambda_{0}$ is at its minimum, $\bar{z}=0$ and $G>0$ for any $\bar{z}_{F}>0$; and (iii) $d G / d \lambda_{0}<0$, since $\partial G / \partial \bar{z}<0, d \bar{z} / d \lambda_{0}>0$, and $d \bar{z}_{F} / d \lambda_{0}=0$ (when $\left.\iota=1\right)$.

Last, we show that $d \tilde{Q} / d \mu<0$ or the following is true:

$$
\frac{d \tilde{Q}}{d \mu} \frac{\mu}{\tilde{Q}}=\frac{\mu}{\omega} \frac{d \omega}{d \mu}+\frac{\mu}{1-\bar{z}_{F}} \frac{d \bar{z}_{F}}{d \mu}+\frac{d I}{d \mu} \frac{\mu}{I}<0
$$

We rewrite this inequality as

$$
\left(-\omega \frac{d H}{d \omega}\right)>\left(1-\bar{z}_{F}\right)\left[1+\omega \frac{d \bar{z}_{F}}{d \omega}\left(\frac{1}{1-\bar{z}_{F}}+\frac{k_{F}\left(\bar{z}_{F}\right)}{I}\right)\right]\left(\mu \frac{d H}{d \mu}\right)
$$

and following the same steps as above, further simplify to $I>\bar{z}_{F} k_{F}\left(\bar{z}_{F}\right)$, which is true.

\section{PROOF OF PROPOSITION 4}

Assume $\iota=1$. Let $\tilde{Q}_{\Lambda}^{*} \equiv Q_{\Lambda}^{*} / Q_{N}=(\omega / \gamma) I_{\Lambda}^{*} /\left(1-\bar{z}_{F}\right), \tilde{Q}_{F}^{*} \equiv Q_{F}^{*} / Q_{N}=(\omega / \gamma) I_{F}^{*} /\left(1-\bar{z}_{F}\right)$, and $\tilde{Q}^{*}=\tilde{Q}_{\Lambda}^{*}+\tilde{Q}_{F}^{*}$, where $I_{\Lambda}^{*}=\bar{z}-I_{\Lambda}, I_{F}^{*}=\bar{z}_{F}-\bar{z}-I_{F}$. It is required to show that $d \tilde{Q}^{*} / d \mu>0$, 
$d \tilde{Q}_{\Lambda}^{*} / d \mu<0, d \tilde{Q}_{F}^{*} / d \mu>0$, and $d\left(\tilde{Q}_{F} / \tilde{Q}_{F}^{*}\right) / d \mu<0$.

First, $d \tilde{Q}^{*} / d \mu>0$ since $d \tilde{Q} / d \mu<0$ (from Proposition 3) and $d\left(\tilde{Q}^{*}+\tilde{Q}\right) / d \mu=0$.

Second, $d \tilde{Q}_{\Lambda}^{*} / d \mu<0$ since $\left[d I_{\Lambda}^{*} / I_{\Lambda}^{*}\right] /[d \mu / \mu]=-1$ and A19 holds.

Third, $d \tilde{Q}_{F}^{*} / d \mu>0$ since $d \tilde{Q}_{F} / d \mu<0$ (from Proposition 3) and $d\left(\tilde{Q}_{F}+\tilde{Q}_{F}^{*}\right) / d \mu>0$. It is true that $d\left(\tilde{Q}_{F}+\tilde{Q}_{F}^{*}\right) / d \mu>0$ since the following inequality holds:

$$
\begin{gathered}
\frac{\mu}{\omega} \frac{d \omega}{d \mu}+\frac{\mu}{1-\bar{z}_{F}} \frac{d \bar{z}_{F}}{d \mu}>\frac{\mu}{I_{F}+\gamma^{-1} I_{F}^{*}}\left[\frac{d I_{F}}{d \mu}+\frac{1}{\gamma} \frac{d I_{F}^{*}}{d \mu}\right], \quad \text { where } \\
\frac{d I_{F}}{d \mu}=-\frac{I_{F}}{\mu}+k_{F}\left(\bar{z}_{F}\right)\left[\frac{\bar{z}_{F}}{\mu}+\frac{d \bar{z}_{F}}{d \mu}\right] \quad \text { and } \frac{d I_{F}^{*}}{d \mu}=-\frac{I_{F}^{*}}{\mu}+\left[1-k_{F}\left(\bar{z}_{F}\right)\right]\left[\frac{\bar{z}_{F}}{\mu}+\frac{d \bar{z}_{F}}{d \mu}\right] .
\end{gathered}
$$

Using (A11), A15), and (A26), we rewrite A25) as

$$
\left(-\omega \frac{d H}{d \omega}\right)<\left(1-\bar{z}_{F}\right)\left[1+\omega \frac{d \bar{z}_{F}}{d \omega}\left(\frac{1}{1-\bar{z}_{F}}+\frac{1-(1-\gamma) k_{F}\left(\bar{z}_{F}\right)}{\gamma I_{F}+I_{F}^{*}}\right)\right]\left(\mu \frac{d H}{d \mu}\right),
$$

and following the same steps as in proving that (A16) holds, we further simplify (A27) to $I_{\Lambda}<\sigma \bar{z}$, which is true.

Last, $d\left(\tilde{Q}_{F} / \tilde{Q}_{F}^{*}\right) / d \mu<0$ since $d \tilde{Q}_{F}^{*} / d \mu>0$ and $d \tilde{Q}_{F} / d \mu<0$.

\section{PROOF OF PROPOSITION 2b}

Assume $\lambda=\lambda_{0}$ and $\iota>1$. It is required to show that $d \bar{z} / d \mu<0$ and $d \bar{z}_{F} / d \mu<0$.

First, we show that $d \bar{z} / d \mu<0$. Setting $\lambda=\lambda_{0}$, we rewrite $(\mathrm{A} 8)$ as follows:

$$
Z(\bar{z}) \equiv \frac{\lambda_{0}}{\tau}-\frac{r+\iota \mu \bar{z}}{r+\mu \bar{z}}=0 .
$$

By the implicit function theorem, $d \bar{z} / d \mu=-Z_{\mu} / Z_{\bar{z}}=-\bar{z} / \mu<0$.

Second, we show that $d \bar{z}_{F} / d \mu<0$. This requires that A15 holds, where $d H / d \omega=H_{\omega}+$ $H_{\bar{z}_{F}} d \bar{z}_{F} / d \omega$ (since $d \bar{z} / d \omega=0$ ) and $d H / d \mu=H_{\mu}+H_{\bar{z}_{F}} d \bar{z}_{F} / d \mu+H_{\bar{z}} d \bar{z} / d \mu$, which still results in (A13). As in the proof of Proposition 2, we find that $d \bar{z}_{F} / d \mu<0$ if $A>B$ in (A17), where now $I=I_{\Lambda}+I_{F}, I_{\Lambda}=\int_{0}^{\bar{z}} k_{\Lambda}(z) d z, I_{F}=\int_{\bar{z}}^{\bar{z}_{F}} k_{F}(z) d z, k_{\Lambda}(z) \equiv[1+\iota q z]^{-1}, k_{F}(z) \equiv[1+q z]^{-1}$. When $\iota \neq 1, A>B$ holds under the following sufficient condition: $\iota \leq 2$. To show this, we proceed in two steps. First, we show that (1) $d A / d \lambda_{0}<0$ and $d B / d \lambda_{0}>0$. This is because (i) $d \omega / d \lambda_{0}<0$ since $d H / d \omega<0$ and $d H / d \lambda_{0}=H_{\bar{z}}\left(d \bar{z} / d \lambda_{0}\right)<0$; and (ii) $d A / d \omega>0$ and $d B / d \omega<0$ since 
$k_{F}\left(\bar{z}_{F}\right)=\left[1+q \bar{z}_{F}\right]^{-1}$ and $\bar{z}_{F}=\left(\tau \omega^{\sigma-1}-1\right) r / \mu$ from A6). Second, we show that $A>B$ at $\lambda_{0} \rightarrow \lambda_{0}^{\max }=\tau[r+\iota \mu] /[r+\mu]$ provided $\iota \leq 2$. If $\lambda_{0} \rightarrow \lambda_{0}^{\max }$, then $\bar{z} \rightarrow 1$ and $\bar{z}_{F} \rightarrow 1$ (provided $L^{*} / L \rightarrow \infty$, otherwise $\bar{z}_{F}<\bar{z}$ and no FDI occurs in an equilibrium) and so $I \rightarrow \int_{0}^{1} k_{\Lambda}(z) d z$ and $\omega^{\sigma-1} \rightarrow(1+\mu / r) / \tau$. It follows that $A>B$ if the following is true:

$$
\frac{\sigma-I}{\sigma-1}>\left(1+\frac{r}{\mu}\right)\left(k_{F}-I\right)
$$

where $I=\int_{0}^{1} k_{\Lambda}(z) d z=(\iota q)^{-1} \ln (1+\iota q)$ and $k_{F}=[1+q]^{-1}$. This inequality holds if $\iota \leq 2$ (since $I<1$ and if $\iota \leq 2, I>k_{F}$ for any $q$ ). Thus, $d \bar{z}_{F} / d \mu<0$ for any $\lambda_{0}$ when $\iota \leq 2$.

\section{PROOF OF PROPOSITION 5}

From the proof of Proposition $3, d \tilde{Q}_{F} / d \mu<0$ if $G>0$ in A23. Despite $d \bar{z}_{F} / d \lambda_{0} \neq 0$ when $\iota \neq 1$, A23 continues to hold because $\partial G / \partial \bar{z}_{F}>0, d \bar{z}_{F} / d \omega>0$, and $d \omega / d \lambda_{0}<0$. Next A24 simplifies to $I_{\Lambda}+I_{F}>\bar{z}_{F} k\left(\bar{z}_{F}\right)$, which holds provided $\iota \leq 2$. To show this, we use $I_{\Lambda}=q^{-1} \ln (1+q \bar{z})$, $I_{F}=q^{-1} \ln \left[\left(1+q \bar{z}_{F}\right) /(1+q \bar{z})\right]$, and $k\left(\bar{z}_{F}\right)=\left(1+q \bar{z}_{F}\right)^{-1}$ and rewrite $I_{\Lambda}+I_{F}>\bar{z}_{F} k\left(\bar{z}_{F}\right)$ as follows: $G+\iota^{-1} \ln [1+\iota q \bar{z}]>0$. This inequality holds for any $\lambda_{0}$ if it holds for $\lambda_{0}^{\max }$, in which case $\bar{z}_{F}=\bar{z}$. Setting $\bar{z}_{F}=\bar{z}$, we rewrite this inequality as $\ln [1+\iota q \bar{z}]-\iota q \bar{z} /[1+q \bar{z}]>0$, which holds for any $q \bar{z}$ provided $\iota \leq 2$. Thus when $\iota \leq 2$, A24 holds and $d \tilde{Q} / d \mu<0$. The proofs of the remaining results in Propositions 3 and 4 are unchanged.

\section{PROOF OF PROPOSITION 6}

If $\lambda=\lambda_{0} /(1+\mu z)$ and $\iota>1$, the cut-off $\bar{z}$ is determined by $\mathrm{A} 8$. It follows that $d \bar{z} / d \mu=-\bar{z} / \mu$. The proofs of the remaining results in Propositions $2 \mathrm{~b}$ and 5 are unchanged.

\section{References}

[1] Anand, B. N. and T. Khanna, 2000. The Structure of Licensing Contracts. The Journal of Industrial Economics, 48(1), 103-135.

[2] Antràs, P., 2005. Incomplete Contracts and the Product Cycle, American Economic Review 95, 1054-1073.

[3] Bilir, K., 2014. Patent Laws, Product Lifecycle Lengths, and Multinational Activity, American Economic Review, 104(7), 1979-2013 
[4] Branstetter, L., R. Fisman, and F. Foley, 2006. Does Stronger Intellectual Property Rights Increase International Technology Transfer? Empirical Evidence from U.S. Firm-Level Data. Quarterly Journal of Economics 121, 321-349.

[5] Branstetter, L., R. Fisman, F. Foley, and K. Saggi, 2011. Does Intellectual Property Rights Reform Spur Industrial Development? Journal of International Economics 83, 27-36, 2011.

[6] Branstetter, L. and K. Saggi, 2011. Intellectual Property Rights, Foreign Direct Investment, and Industrial Development. Economic Journal 121, 1161-91.

[7] Caves, R.E., Crookell, H., Killing, J.P., 1983. The Imperfect Market for Technology Licenses. Oxford Bulletin of Economics and Statistics 45, 249-267.

[8] Ethier, W. J., 1986. The Multinational Firm. Quarterly Journal of Economics 101, 805-833.

[9] Ethier, W. J. and Markusen, J. R., 1996. Multinational Firms, Technology Diffusion and Trade. Journal of International Economics 41, 1-28.

[10] Gallini, N. T. and Wright, B.D., 1990. Technology Transfer under Asymmetric Information. Rand Journal of Economics 21, 147-160.

[11] Glass, A. J. and K. Saggi, 2002a. Intellectual Property Rights and Foreign Direct Investment. Journal of International Economics 56, 387-410.

[12] Glass, A. J. and K. Saggi, 2002b. Licensing versus direct investment: implications for economic growth. Journal of International Economics 56, 131-153.

[13] Griffith, R., Redding, S. and Simpson, H., 2009. Technological Catch-up and Geographic proximity. Journal of Regional Science 49, 689-720.

[14] Grossman, G.M. and E. Helpman, 1991. Innovation and Growth in the Global Economy, Cambridge, MIT press.

[15] Grossman, G.M. and E. L.C. Lai, 2004. International Protection of Intellectual Property. American Economic Review 94, 1635-1653.

[16] Helpman, E., 1993. Innovation, imitation, and intellectual property rights. Econometrica 61, 1247-1280.

[17] Horstmann, I., and J. R. Markusen, 1987. Licensing versus direct investment: A model of internalization by the multinational enterprise. Canadian Journal of Economics, 464-481. 
[18] Ivus, O., 2011. Trade-Related Intellectual Property Rights: Industry Variation and Technology Diffusion. Canadian Journal of Economics 44(1), 201-226.

[19] Ivus, O., Park, W., and Saggi, K. 2015. Patent Protection and the Industrial Composition of Multinational Activity: Evidence from U.S. Multinational Firms, Working Paper.

[20] Javorcik, B., 2004. The Composition of Foreign Direct Investment and Protection of Intellectual Property Rights in Transition Economies. European Economic Review 48, 39-62.

[21] Lai, E., 1998. International Intellectual Property Rights Protection and the Rate of Product Innovation. Journal of Development Economics 55, 133-153.

[22] Lee, J-Y and E. Mansfield, 1996. Intellectual Property Protection and U.S. Foreign Direct Investment. The Review of Economics and Statistics 78, 181-186.

[23] Levin, R. C., Klevorick, A. K., Nelson, R. R., Winter, S. G., Gilbert, R., and Z. Griliches, 1987. Appropriating the returns from industrial research and development. Brookings papers on economic activity, 1987(3), 783-831.

[24] Mansfield, E., Schwartz, M., and S. Wagner, 1981. Imitation costs and patents: an empirical study. The Economic Journal, 91(364), 907-918.

[25] Markusen, J.R., 2001. Contracts, Intellectual Property Rights, and Multinational Investment in Developing Countries. Journal of International Economics 53, 189-204.

[26] Markusen, J.R., 1995. The Boundaries of Multinational Enterprises and the Theory of International Trade. Journal of Economic Perspectives 9, 169-190.

[27] Maskus, K.E., 2000. Intellectual Property Rights in the Global Economy, Institute for International Economics, Washington DC.

[28] Park, W., 2008. Intellectual Property Rights and International Innovation, in, Maskus, K., ed., Frontiers of Economics and Globalization: Intellectual Property Rights and Globalization, Elsevier, Amsterdam.

[29] Poole, J., 2013. Knowledge Transfers from Multinationals to Domestic Firms: Evidence from Worker Mobility. Review of Economics and Statistics 95(2), 393-406.

[30] Rycroft, R. W. and D. E. Kash, 1999. The complexity challenge: Technological innovation for the 21st century. CengageBrain. com.

[31] Yang, G. and K. E. Maskus, 2001. Intellectual property rights, licensing, and innovation in an endogenous product-cycle model. Journal of International Economics 53, 169-87. 